IZA DP No. 8951

The Effects of Binding and Non-Binding Job Search Requirements

Patrick Arni

Amelie Schiprowski

March 2015 


\title{
The Effects of Binding and Non-Binding Job Search Requirements
}

\author{
Patrick Arni \\ IZA, University of Lausanne (DEEP) \\ and Aarhus University (CAFE) \\ Amelie Schiprowski \\ IZA, DIW Berlin \\ and University of Potsdam
}
Discussion Paper No. 8951
March 2015

\author{
IZA \\ P.O. Box 7240 \\ 53072 Bonn \\ Germany \\ Phone: +49-228-3894-0 \\ Fax: +49-228-3894-180 \\ E-mail: iza@iza.org
}

\begin{abstract}
Any opinions expressed here are those of the author(s) and not those of IZA. Research published in this series may include views on policy, but the institute itself takes no institutional policy positions. The IZA research network is committed to the IZA Guiding Principles of Research Integrity.

The Institute for the Study of Labor (IZA) in Bonn is a local and virtual international research center and a place of communication between science, politics and business. IZA is an independent nonprofit organization supported by Deutsche Post Foundation. The center is associated with the University of Bonn and offers a stimulating research environment through its international network, workshops and conferences, data service, project support, research visits and doctoral program. IZA engages in (i) original and internationally competitive research in all fields of labor economics, (ii) development of policy concepts, and (iii) dissemination of research results and concepts to the interested public.
\end{abstract}

IZA Discussion Papers often represent preliminary work and are circulated to encourage discussion. Citation of such a paper should account for its provisional character. A revised version may be available directly from the author. 


\section{ABSTRACT}

\section{The Effects of Binding and Non-Binding Job Search Requirements*}

Job search requirements constrain the effort choice of unemployment insurance recipients by enforcing a minimum number of monthly applications. This paper is the first to assess how individual search effort, job finding and job stability react to this constraint. Standard job search theory predicts that requirements affect each job seeker relative to her unconstrained effort choice. Therefore, the behavioral treatment intensity of interest is the incremental effort necessary to comply with the requirement. Using novel Swiss register data, we measure this intensity as the difference between the individual requirement threshold and the search effort provided just before requirement imposition. Our econometric approach exploits that conditional on a broad set of choice fixed effects - the match between the job seeker's unconstrained effort choice and the caseworker's requirement setting behavior is arbitrary. Therefore, it provides exogenous variation in the treatment assignment. We find that binding search requirements that exceed the job seeker's unconstrained effort choice, increase job finding in a substantial way. These effects are highly heterogeneous with respect to the job seeker's characteristics. They come at the cost of increased non-compliance and sanction imposition rates. Moreover, binding requirements have striking negative effects on job stability. Finally, we find that non-binding requirements can also affect search outcomes. This suggests that requirements can operate as signals, thereby generating behavioral effects that are not predicted by standard job search theory.

JEL Classification: J64, J65

Keywords: job search behavior, unemployment insurance, incentive effects

Corresponding author:

Amelie Schiprowski

IZA

P.O. Box 7240

53072 Bonn

Germany

E-mail: schiprowski@iza.org

\footnotetext{
* We thank John Abowd, Marco Caliendo, David Card, Stefano DellaVigna, Luke Haywood, Hilary Hoynes, Rafael Lalive, Xingfei Liu, Sebastian Siegloch, Till von Wachter, Conny Wunsch as well as seminar participants at IFAU Uppsala, SFI Copenhagen, Aarhus University, VATT Helsinki, ifo Dresden, IZA Bonn, University of Potsdam, DIW Berlin, the Brucchi Lucchino Workshop 2014 Naples, the University of Warwick Phd conference 2015, the RES Annual Meeting 2015 and the SOLE/EALE World Conference 2015 for helpful comments and suggestions. We are very grateful to the Swiss State Secretariat of Economic Affairs (SECO) for its helpful and generous support, in particular Jonathan Gast for the data and information provision. We also thank BECO and Remo Frei for their support in the realization of a caseworker survey in the canton of Bern. Amelie Schiprowski acknowledges financial support of the German Academic Foundation.
} 


\section{Introduction}

Although the enforcement of minimum search effort has become a core element of modern unemployment insurance (UI), little is known about its effects on search behavior and outcomes: how do individuals change their effort choice when it is constrained by a job search requirement? Do constraints on search effort reduce intrinsic effort? Can required effort changes translate into increased job finding and does this compromise job stability? Systematic evidence on these questions is broadly missing, as the job seeker's constrained and unconstrained effort choices are unobserved in standard data sources. This paper addresses this gap by presenting detailed empirical results from novel, individual-level register data that report effort choices.

Job search requirements - the setting of a minimum number of applications to be submitted per time span - have become a widely used instrument among OECD countries (Venn 2012). In recent years, their strength has risen among both U.S. states and European countries. Requirements condition benefit receipt on sufficient search effort from the beginning of the spell onwards, while leaving the overall level of insurance unaffected. This feature distinguishes requirement policies from general benefit cuts, as they provide an instrument for more targeted effort enforcement. ${ }^{1}$ The job seeker's compliance with the requirement is monitored by the Public Employment Service (PES) and enforced by a credible sanction threat: if the number of applications submitted is lower than the required number, job seekers face a high risk of seeing their benefits temporarily cut.

The enforcement of requirements is usually motivated by the assertion that generous UI benefits can lead to the under-provision of search effort. This phenomenon is discussed in a broad strand of empirical literature on the impacts of benefit generosity in UI schemes. The evidence suggests that high benefit payments and a long benefit duration reduce the unemployment exit rate (e.g. Meyer 1990, Katz and Meyer 1990, Hunt 1995, Card and Levine 2000, Chetty 2008, Lalive 2008, Schmieder et al. 2012, Caliendo et al. 2013). However, direct empirical evidence on how individual effort choices contribute to these aggregate effects is absent, as standard UI registers do not provide data on effort provision. Novel Swiss register data allow us to measure both the requirement constraint and a proxy for unconstrained effort at the beginning of each individual unemployment spell. We define the difference between these two variables as the treatment intensity of interest and propose a method to evaluate its effects. We can thereby establish a direct link between a required change in search effort and the job seeker's outcomes. While this link is confirmed by standard job search theory, it has to our knowledge not yet been tested empirically. A few contributions investigate how the introduction or strengthening of a job search monitoring regime

\footnotetext{
${ }^{1}$ In the theoretical literature on optimal UI, Pavoni and Violante (2007) show that using job search monitoring as an additional instrument can be welfare improving, as compared to a situation where changes in benefit levels is the only means to affect effort provision.
} 
changes job finding rates and job quality (Van den Berg and Van der Klaauw 2006, McVicar 2008, Petrongolo 2008, Manning 2009, Hullegie and Van Ours 2014). These studies can however not separately identify the effect of required effort changes, as search monitoring regimes include a whole "package" of treatments, including requirements, the knowledge of being monitored and the incidence of benefit sanctions. Another set of studies exploits variation resulting from field experiments run in different U.S. states (Johnson and Klepinger 1994, Meyer 1995, Klepinger et al. 2002, Ashenfelter et al. 2005). While some of these studies allow separately identifying the effect of changes in the requirement strength and the enforcement mechanisms, they are unable to study required effort changes at the individual level.

Our empirical analysis focuses on the individual effort constraint and assesses whether it induces reactions that are in line with standard search theory. A small and growing literature on behavioral labor economics identifies departures from standard rational theories and proposes alternative behavioral explanations for common labor topics. ${ }^{2}$ In the context of job search, this literature suggests that the job seeker's effort decision does not entirely follow the rule of rational behavior, as it may be influenced by hyperbolic discounting (DellaVigna and Paserman 2005), biased beliefs (Spinnewijn 2013; Falk et al. 2006) and reference-dependent preferences (Della Vigna et al. 2014). We contribute to this literature by analyzing how the individual behaves when confronted with a requirement constraint that differs from her preferred effort choice.

As a starting point, we derive predictions from a basic job search model with enforced requirements, as introduced in Abbring et al. (2005) on the grounds of Mortensen (1987). ${ }^{3}$ A key feature of search requirements is that they affect job seekers relative to their unconstrained effort choices: a requirement is binding when it exceeds the effort that the job seeker would provide in its absence; it is non-binding otherwise. Binding requirements are predicted to increase search effort, but the possibility of non-compliance makes this effect non-linear: the job seeker's cost of compliance increases with the difference between her unconstrained effort and the requirement. Consequently, non-compliance rates and the incidence of benefit sanctions are expected to rise, since taking the risk of benefit cuts becomes marginally more attractive. As binding requirements increase search effort and reduce the reservation wages of both compliant and non-compliant individuals, they are expected to increase job finding and reduce job quality. By contrast, non-binding requirements do in the model not affect the job seeker's behavior and outcomes.

We bring these predictions to a reduced-form framework and define the treatment intensity of interest as the distance from the individual's requirement threshold to her unconstrained effort level at the beginning of the spell. We thus model the degree to which the requirement is binding or

\footnotetext{
${ }^{2}$ Examples include work on pay equity (Kahnemann et al. 1986; Card et al. 2012) or reference-dependent labor supply (Fehr and Goette 2007).

${ }^{3} \mathrm{~A}$ similar version is introduced in Lalive et al. (2005).
} 
non-binding to the individual effort choice, at a stage of the unemployment spell at which benefit exhaustion is not yet relevant for the job seeker's behavior. Our database reports individual-level requirement thresholds as well as provided search effort measured as the number of monthly job applications. We start our empirical analysis by showing that the effort level provided by the job seeker before she learned about her individual requirement reveals substantial information on her cost of effort. We argue that this level can therefore be used as a proxy for the job seeker's unconstrained search effort.

We then proceed to identifying the causal effect of the individual treatment intensity on the job seeker's compliance behavior, job finding and job stability. For identification we exploit that there is randomness in the match between the job seeker's effort choice and the caseworker's requirement setting behavior, which generates exogenous variation in the individual treatment intensity. To isolate this randomness, we apply several sets of fixed effects that control for the endogenous components in the job seeker's and the caseworker's behavior: first, we control for the job seeker's unconstrained effort level constant, which takes into account the individual search productivity or motivation. Second, we address that requirement thresholds are allocated on a non-random basis by caseworkers at their first meeting with the job seeker. Our key argument is here that selection occurs with respect to the level of the requirement, not with respect to its difference to the pre-requirement effort choice. Holding this level constant therefore amounts to excluding the caseworker's assessment of a job seeker's characteristics from the variation in the treatment intensity. To this purpose, we introduce controls for the level of the requirement assigned to the individual, as deviations from the caseworker's median requirement choice. Third, we add caseworker effects, which control for other potentially correlated policy choices and local labor market conditions. We provide evidence on the quasi-randomness of the assignment process conditional on these fixed effects.

Our analysis results in the following main findings: we first confirm the theoretical predictions that the elasticity of search effort with respect to binding requirements is strong but imperfect, as compliance becomes costly when the requirement increases. Our results show that the probability of non-compliance rises substantially in response to a required increase in effort. When the required increase in search effort relative to the unconstrained choice is high, job seekers find it more attractive to incur the risk of a benefit sanction. This translates into increased sanction imposition rates. Policy makers should keep these non-compliance effects in mind when designing requirement thresholds.

We then identify a substantial positive effect of binding search requirements on job finding, in particular at early stages of the unemployment spell. If a job seeker has to increase her search effort due to the requirement by one application, her probability of finding a job within six months will increase on average by about .5 percentage points. This effect is non-linear (concave), which 
suggests that policy makers cannot maximize job finding rates simply by maximizing requirement levels. Further, these effects differ with respect to the labor demand situation: they are strongest in local labor markets in which vacancy rates are high. It is also striking that job finding rates of low service occupations and low education groups react most. It appears that job finding in these groups is most responsive to the quantity of job applications.

The requirement-driven increase in job finding goes along with larger job instability. Estimates of the unemployment recurrence rate - i.e. the risk of returning to unemployment within 6 months after job finding - show remarkable effects: the risk that individuals take up temporary or instable jobs that end up in a new unemployment spell proves substantially higher when individuals face strongly binding requirements. We even find that the positive effect of binding requirements on early job finding is driven entirely by exits to unstable jobs.

Finally, our results reveal interesting insights into the role of non-binding requirements: these also affect job search outcomes, which is not in line with the predictions of standard job search theory. After receiving a search requirement, job seekers move their realized search effort towards the requirement threshold, also when their unconstrained search level was significantly higher. This reduction in search effort negatively affects the probability of job finding during the first three months of unemployment. At the same time, non-binding requirements positively affect job stability. This finding suggests that the search requirement operates not only when it represents a binding constraint to the individual that is enforced by a benefit sanction. It also works by signaling a reference point on the optimal search quantity and can, through this channel, move the effort of all job seekers towards the requirement threshold. The importance of reference points in job search has already been highlighted by DellaVigna et al. (2014), who suggest that search intensity increases when individuals experience income losses compared to their situation in the previous period. In our analysis, the job seeker's reference point is not his individual past situation, but the signal given by the search requirement. It appears that job seekers are very reactive to interventions that signal the "optimal" search quantity as defined by the policy maker.

Our paper is structured as follows: we begin by discussing the theoretical prediction on the intensive margin effects of requirements on job search behavior and job finding (section 2). Section 3 presents the institutional background and the structure of our data sources. In section 4, we provide descriptive evidence on the behavior of constrained and unconstrained search effort. Section 5 discusses our econometric model and section 6 presents our results. Section 7 concludes. 


\section{Theoretical Discussion}

The Model We desicuss theoretical predctions on the effects of search requirements on individual behavior based on a framework developed by Abbring, van den Berg and van Ours (2005). ${ }^{4}$ The authors introduce requirements and benefit sanctions in a job search model as proposed by Mortensen (1987). It is important to note that the used definition of search effort is limited to its quantitative dimension. This is mainly due to the design of search requirements in OECD countries, which target the number of applications to be submitted. ${ }^{5}$ Also note that our discussion refers to a situation in which the job seeker's benefit exhaustion is not yet relevant. Our entire analysis will focus on required effort changes at early stages of the unemployment spell.

The search requirement $s_{r}$ and its enforcement, i.e. the probability $p_{0}$ of being sanctioned in case of non-compliance, affect the job seeker's behavior before the possible occurrence of a sanction. According to a slightly adopted version of Abbring, van den Berg and van Ours (2005), ${ }^{6}$ the job seeker's value function before any enforcement writes:

$$
\rho R=\max _{s}\left[b-c(s)+\lambda(s) \int_{\phi}^{\infty}\left(\frac{w}{\rho}-R\right) d F(w)+I\left(s<s_{r}\right)\left(1-\frac{s}{s_{r}}\right) p_{0}\left(R_{s a n c}-R\right)\right]
$$

where $R_{\text {sanc }}<R$ is the expected value of unemployment after benefits have been cut by the sanction amount. ${ }^{7} b$ is the unemployment benefit, $s$ the search effort measured as the realized number of applications and $w$ the wage of the final job match. $\phi$ denotes the reservation wage, which equals $\rho R$ after optimization. When no requirement policy is in place, the job seeker chooses the optimal effort level $s^{*} . s^{*}$ results from a trade-off between the marginal cost of effort $c^{\prime}(s)$ and its marginal benefit, which involves an increase in the job arrival rate $\lambda^{\prime}(s)$ and the associated differential in value between employment and unemployment $\int_{\phi}^{\infty}\left(\frac{w}{\rho}-R\right) d F(w)$.

Given $s^{*}$, the job seeker chooses her provided level of effort $s$ in a system with requirements. The requirement threshold enters through the term $I\left(s<s_{r}\right)\left(1-\frac{s}{s_{r}}\right) p_{0}\left(R_{\text {sanc }}-R\right)$ : in case the job seeker provides a search effort that is lower than the requirement $\left(I\left(s<s_{r}\right)=1\right)$, there is an exogenous probability $p_{0}$ that the job seeker moves to the sanctioned state. This probability becomes more salient when the distance from the provided to the required effort increases $\left(1-\frac{s}{s_{r}}\right)$.

It depends on the difference between the requirement and the job seeker's unconstrained effort,

\footnotetext{
${ }^{4}$ Lalive et al. (2005) present a very similar framework in their analysis of UI benefit sanctions.

${ }^{5}$ Note that in most countries, monitoring of compliance with the requirement also includes guaranteeing some minimum quality standard, as caseworkers can e.g. ask for the application letters sent out. This is also the case in Switzerland (c.f. section 3).

${ }^{6}$ We introduce the term $1-\frac{s}{s_{r}}$ to account for the empirical fact that the probability of sanction becomes more likely when the ratio of provided to required effort becomes high.

${ }^{7}$ Abbring et al. (2005) assume for simplicity that a sanction reduces the present value of unemployment for the remaining unemployment spell. We follow this assumption.
} 
$\Delta_{s_{r}}^{*}=s_{r}-s^{*}$, how individual search behavior is affected by the presence of the requirement. The following three cases, which are illustrated in Figure 1, can be distinguished:

(I) $\Delta_{s_{r}}^{*} \leqslant 0$ : the job seeker faces a requirement which is lower than her unconstrained effort level. In this case, all search outcomes are therefore unaffected by the search requirement and the job seeker continues providing $s^{*}$.

(II) $\Delta_{s_{r}}^{*}>0$ and compliance: the job seeker has to increase search effort by $\Delta_{s_{r}}^{*}$ to to comply with the requirement. In case II in Figure 1, the individual cost of complying is lower than the cost of facing the risk of a benefit sanction. The job seeker therefore chooses to submit $s=s_{r}$ applications. Since this effort level is sub-optimal from the individual perspective, this behavioral change is associated with a decrease in the present value of unemployment and thus the reservation wage.

(III) $\Delta_{s_{r}}^{*}>0$ and non-compliance: beyond an individual-specific threshold, the job seeker's present value of submitting less applications than required and incurring a given risk of sanction is larger than the present value of complying. In other words, the cost of compliance is too high. The job seeker now chooses an effort level $s<s_{r}$ and does therefore not comply. As the probability of a benefit sanction is now positive, the job seeker's present value of unemployment again decreases. Note that the provided effort still exceeds $s^{*}$ because providing a level of search effort that is close to the requirement reduces the sanction probability. Also note that the dashed line in Figure 1 is an approximation and could be non-linear, depending in particular on the functional form of the job seeker's effort cost.

Figure 1: Illustration of Theoretical Predictions

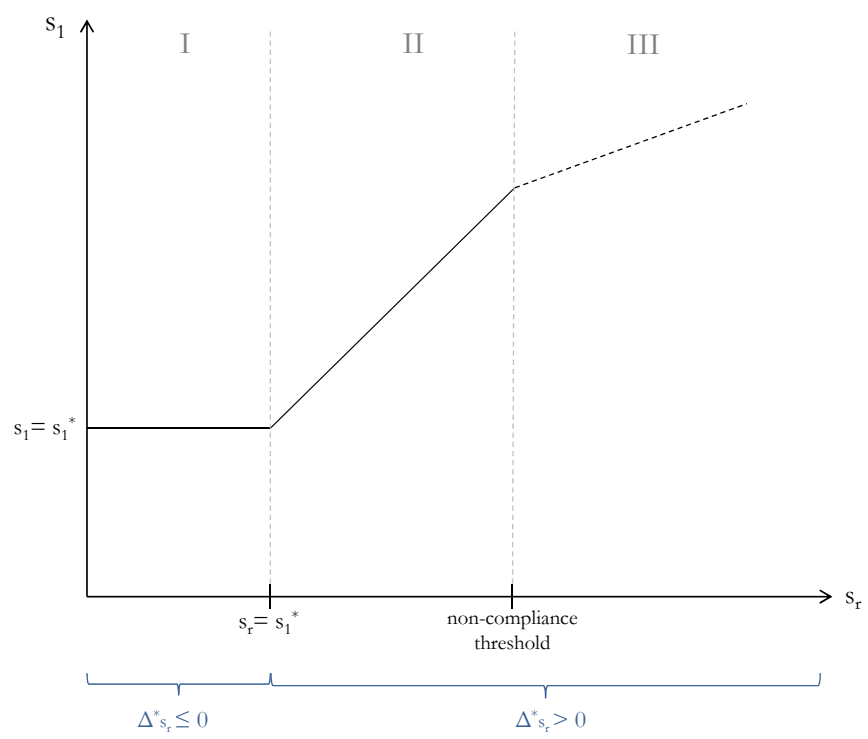


Predictions for the Empirical Analysis The above reasoning shows that the difference between $s^{*}$ and $s_{r}$, which we denoted as $\Delta_{s_{r}}^{*}$, is at the center of the requirement's effects on job search behavior. The following main predictions on the effects of $\Delta_{s_{r}}^{*}$ arise and will be taken to our empirical approach:

1. If $\Delta_{s_{r}}^{*}<0$, the requirement is non-binding for the individual job seeker. According to job search theory, it does not induce any changes in search behavior of rational agents.

2. If $\Delta_{s_{r}}^{*}>0$, the requirement is binding from the individual's perspective. An increase in $\Delta_{s_{r}}^{*}$ is now predicted to have the following effects:

i) The cost of compliance increases with $\Delta_{s_{r}}^{*}$. Given a fixed amount and probability of sanction, a high cost of compliance makes non-compliance, i.e. the provision of $s_{1}<s_{r}$, relatively more attractive. Therefore, we expect the incidence of non-compliance and the sanction imposition rate in our sample to increase with $\Delta_{s_{r}}^{*}$.

ii) Search effort increases and reservation wages decrease with $\Delta_{s_{r}}^{*}>0$. We therefore expect job finding rates to increase. Note that this increase is probably not linear, since the cost of effort and the responsiveness of labor demand to additional job applications can be non-linear.

iii) Due to the reduction in the job seeker's reservation value both under compliance and under non-compliance, we expect the increase in job finding rates to go along with a decrease in job quality. ${ }^{8}$

\section{Institutions and Data}

\subsection{Institutional Background}

The Swiss Unemployment Insurance (UI) System The Swiss UI is a typical representation of an OECD UI system, showing strong similarities to systems implemented in Germany, Denmark, the UK and the US, for instance. Job seekers are entitled to UI benefits if they meet two main prerequisites. First, they must have contributed for at least six months in the two years prior to registering at the Public Employment Service (PES). ${ }^{9}$ The contribution period is extended to 12 months for those individuals who have been registered at least once in the three previous years. Second, job seekers must be able to be "employable" in a regular job. If these criteria are not met, there is the possibility to collect social assistance. The potential duration of unemployment

\footnotetext{
${ }^{8}$ In our empirical framework, we measure job quality as job stability.

${ }^{9}$ To be eligible for the full benefit period, the contribution period extends to 12 or 18 months, depending on the individual situation.
} 
benefits is two years for eligible job seekers. The replacement ratio is between $70 \%$ and $80 \%$ of previous earnings, depending on the individual family situation and the level of past earnings.

The organization of counseling and monitoring is ensured by Public Employment Service (PES) offices, which are the organizational unit of caseworkers. When individuals register at the PES office, they are assigned to a caseworker based upon previous industry, previous occupation, place of residence or the caseworker's availability (caseload formula).

Job Search Monitoring in Switzerland Swiss UI law requires individuals to start actively searching for work from the moment that they learn about their future unemployment. ${ }^{10}$ This is usually three months before a job loss becomes effective, as employers have to announce a layoff three months in advance. Before the first meeting with the caseworker, the job search obligation does not include a fixed requirement threshold. It thus appeals to the job seeker's own definition of active job search. After having entered formal unemployment, job seekers are informed about their individual search requirement threshold when they first meet their caseworker. The first meeting usually takes place around three weeks after registration (c.f. Table 13 in the Appendix for details). The requirement threshodn defines the minimum number of applications which the job seeker is obliged to submit to avoid benefit sanctions in the form of temporary benefit cuts. This number varies between 1 and 15 monthly applications in our sample (c.f. section 4.2).

The PES is obliged by law to monitor and enforce the compliance with the job search obligation before and after the job seeker enters formal unemployment. As a consequence, the database of job search monitoring creates by default an entry for the pre-requirement effort. Caseworkers fill this entry by asking job seekers to report their search activity previous to the first meeting. They are obliged to ask for proofs of this activity and enforce benefit cuts if they conclude that the prerequirement effort was insufficient. Once the requirement was announced, the application activity is documented in a monthly "protocol of search effort", which job seekers submit until the $5^{\text {th }}$ day of the following month. The compliance with the search requirement threshold is monitored by the caseworker. Caseworkers are again supposed to ask for proofs of submitted applications during their regular meetings with the job seeker. In addition, the submission of applications can be checked by contacting the human resources department of the potential employer reported on the proticol. Once a non-compliance with the search requirement is detected, benefit cuts can enter into force. In our sample, a job seeker who does not comply with the requirement at least once during the unemployment spell ${ }^{11}$ has a chance of $60 \%$ to receive at least one warning that a non-compliance has been formally detected and a chance of $45 \%$ to actually receive at least one

\footnotetext{
${ }^{10}$ c.f. State Secretary for Economic Affairs (SECO), 2014: AVIG-Praxis ALE (UI practice guidelines), paragraph B314

${ }^{11}$ We define a non-compliance as the submission of less than $3 / 4$ of required applications.
} 
benefit sanction. The median amount of a sanction is the monetary equivalent of 7 days of UI benefits.

\subsection{Data Sources and Sampling}

Data Sources Our empirical analysis is based on Swiss administrative data. The sample covers all benefit recipients entering UI between January 12010 and December 31 2012. It includes extensive information on entry into and exit from formal unemployment, socio-demographics, potential benefit duration as well as employment and unemployment history including past earnings. ${ }^{12}$ It further reports which PES and caseworker the job seeker was assigned to. We measure the duration of unemployment as the number of days elapsed between the date of registration at the PES and the date of de-registration at which the job seeker's file was closed.

Structure of Data on Search Effort We match these records to the database used by caseworkers to monitor job search effort. It reports the required and realized number of applications for each job seeker on a monthly basis. In addition, we observe when a non-compliance with the requirement is detected by the caseworker and when it results in a cut of benefit payments. A particular feature of the database is that we can also identify the number of applications sent out before the job seeker learned about his requirement, as these are also monitored (c.f. section 3.1). This pre-requirement effort level is denoted $s_{0}$. We show in section 4.3 that $s_{0}$ is not yet influenced by any fixed requirement level and therefore a suitable indicator for what the job seeker herself considers to be the amount of job search that is sufficient for the beginning of the unemployment spell. ${ }^{13}$

The database, whose structure is illustrated in Figure 2, provides three main individual-level parameters of interest for our analysis: the pre-requirement effort level $s_{0}$, the search requirement $s_{r}$ imposed by the caseworker for the unemployment spell and the effort level $s_{t} \mid s_{r}$ provided in month $t$ in response to the requirement. As we focus in this paper on the effort levels provided at the beginning of the job seeker's unemployment spell, we are exclusively interested in $s_{1} \mid s_{r}$.

\footnotetext{
${ }^{12}$ Table 14 shows summary statistics on these variables.

${ }^{13}$ As there is a legal obligation to search for work before the first caseworker meeting, we do not consider $s_{0}$ to be completely unrestricted by the monitoring regime. Nevertheless, it is not influenced by the exact requirement level $s_{r}$, which we argue to be unknown by the job seeker at $t_{0}$. This might hold less for job seekers who have during previous unemployment spells learned about the requirement system. We will in a robustness check exclude these job seekers and show that they do not drive our results.
} 


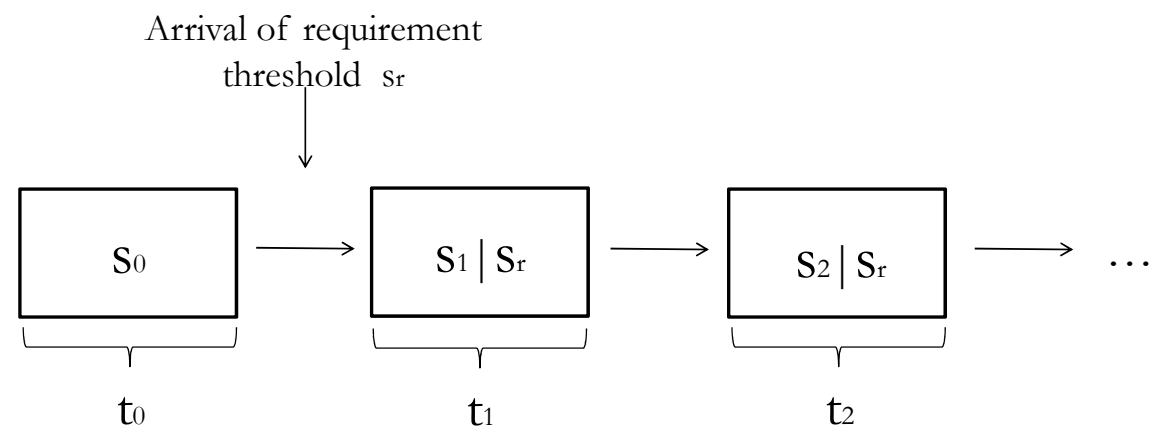

Figure 2: Basic structure of data on job search monitoring

Sampling In principle, our data set contains the entire population of Swiss UI job seekers who enter UI during the sample period. In this paper, we limit our sample to job seekers registered in those cantons where job search monitoring is systematically reported in the central database (to which we have access to). ${ }^{14}$ Our sample contains the cantons Bern, Fribourg, Solothurn, Graubuenden and Tessin, which cover around $25 \%$ of the unemployed population and three different geographic and language regions in Switzerland.

The obligation to engage in active job search needs to be fulfilled in exchange to the payment of UI benefits. Our study aims to identify how the difference between the requirement threshold and the job seeker's unconstrained effort choice affects search behavior Therefore, we want to limit our sample to those job seekers who faced a requirement that was monitored during their unemployment spell. These are job seekers who are full-time unemployed, eligible for UI payments and not eligible for other benefits (in particular disability insurance). We also exclude job seekers who are younger than 20 or older than 55 years, as these might face particular incentives and labor market conditions. In addition, we exclude job seekers whose previous unemployment spell ended less than a month previous to their current registration. These are most likely particular cases to which the institutional setting underlying our analysis does not apply. Further restrictions are imposed by the design of the requirement policy. As our analysis of binding vs. non-binding requirements is conducted at the intensive margin, it only concerns individuals who were subject to the search obligation from the beginning of their spell onwards. Everyone faces this obligation by law, although there are possible exemptions due to the individual's situation. In the data appendix A.1, we describe how we defined those individuals who were systematically affected by the search obligation, as well as the percentages of excluded spells. We there also provide a detailed description of how we extract the variables $s_{0}, s_{r}$ and $s_{1} \mid s_{r}$ from the database on job search

\footnotetext{
${ }^{14}$ Federal Swiss law prescribes the enforcement of job search requirements. Therefore, it is ensured that cantons excluded from our sample participated at the requirement policy. Anecdotal evidence suggests that these cantons have their own system of requirement registration rather than employing the central data base.
} 
monitoring and how we impute requirement thresholds for the $8.2 \%$ of job seekers whose search effort was monitored but whose requirement level is missing in the data. In essence, imputation is straightforward as we know the requirement setting behavior of the caseworker to which each job seeker was assigned. Excluding job seekers with missing requirement thresholds does not affect our results (c.f. robustness analysis).

\section{Descriptive Evidence on Requirement Thresholds and Ef- fort Choices}

We begin this section by showing descriptive evidence on the distribution and the observable determinants of effort choices and requirement levels. We then provide a discussion and descriptive evidence on whether $s_{0}$ is suitable to measure the job seeker's unconstrained effort choice. At the end of this section, we show discuss the distributions of required and realized effort changes.

\subsection{Sample Distributions}

In the following, we document features of the distributions of $s_{0}, s_{r}$ and $s_{1}$. Detailed summary statistics on these variables can be found in Table 12 in Appendix A.2.

Unconstrained Effort $s_{0}$ Figure 3 displays the distribution of $s_{0}$ for the job seekers in our sample. The median job seeker has a level of $s_{0}=6$. Around $20 \%$ of job seekers do not submit any applications before registering at the PES. ${ }^{15}$ a vast majority reports $s_{0}$ within the range of 1 to 20 and around $10 \%$ beyond that range.

[Insert Figure 3]

Search Requirement $s_{r}$ Figure 4a shows how requirement levels are distributed within the considered sample of job seekers. The median requirement is at eight applications per month. Differences in requirement levels result from two main sources of variation. First, PES have different baseline policies that comprise setting higher or lower average requirement levels, as displayed in Figure 4b. Moreover, caseworkers also have preferences for average policies that can deviate from the PES' average policy (Figure 4c). Second, we know from a qualitative caseworker survey ${ }^{16}$ that caseworkers set requirement levels at a personal contact with the job seeker. Therefore, they can differentiate the requirement level according to the job seeker's characteristics observed at the

\footnotetext{
${ }^{15}$ For, $50 \%$ of these job seekers, the caseworker registers insufficient pre-requirement search effort.

${ }^{16}$ Survey among 40 caseworkers in the canton of Bern. More information available on request.
} 
first meeting. We observe parts of these characteristics, such as age, education and occupation, whereas other determinants such as motivation, health and appearance remain unobserved to us. As shown in Figure 4d, most caseworkers distribute two or three different requirement thresholds among their population of job seekers. We will come back to this feature when describing our econometric analysis.

\section{[Insert Figure 4]}

Constrained effort $s_{1} \mid s_{r}$ We measure the constrained search effort $s_{1} \mid s_{r}$ as the effort provided in the first month in which the search requirement was known. Figure 5 displays its distribution. It peaks at the most commonly imposed requirement thresholds $6,8,10,12$, suggesting that most job seekers submit exactly the required number of applications. The share of job seekers with no application activity diminished substantially; around $5 \%$ of job seekers still provide zero effort at $t_{1}$. We observe in the data that these are indeed perceived as non-compliant by the monitoring regime, as around $50 \%$ of them receive a benefit sanction for insufficient effort during the first three month of unemployment (vs. $12 \%$ of job seekers who submit a positive $s_{1}$ ).

\section{[Insert Figure 5]}

\subsection{Observable Determinants of $s_{r}$ and $s_{0}$}

Next, we present some descriptive evidence on the observable determinants of $s_{0}$ and $s_{r}$. Table 1 displays regressions of relevant job seeker characteristics on the two variables, which, for the sake of comparability, all include caseworker fixed effects. Column (1) shows that female job seekers provide on average a higher $s_{0}$. Further, $s_{0}$ increases with age. Individuals from the service sector exert a larger level of $s_{0}$ than those from the blue collar sector. Interestingly, the determinants of the requirement threshold point at least partly in the other direction, as shown in Column (2): female and older job seekers are on average assigned slightly lower requirements. Education, sector and function in the last job are important determinants of $s_{r}$, which is in line with the answers obtained in the caseworker survey. given by caseworkers from Bern in a survey that we run with them. ${ }^{17}$

In Column (3), it is shown that the importance of the different covariates in the requirement setting does not change significantly after introducing fixed effects for $s_{0}$. We will come back to this feature when we discuss our identification strategy.

\section{[Insert Table 1]}

\footnotetext{
${ }^{17}$ Survey among 40 caseworkers in the canton of Bern. More information available on request.
} 


\subsection{The content of $s_{0}$ as a measure of $s^{*}$}

$s_{0}$ is the effort provided by each job seeker in the month before the requirement threshold was announced to him. In order to use it as a measure for $s^{*}$, it needs to be assumed that the reported $s_{0}$ is a valid representation of the job seeker's unconstrained search effort.

A first part of the assumption implies that the job seeker does not lie about his provided effort level $s_{0}$. This is guaranteed by our institutional setting: given that low levels of $s_{0}$ can result in benefit sanctions, there is no incentive for understating $s_{0}$. Overstatement is not feasible, as job seekers are asked to prove their application activity.

The second part of the assumption is less trivial requires that $s_{0}$ indeed reveals the effort level which she would provide if no requirement threshold was to arrive at the beginning of the spell. $s_{0}$ reflects the pre-requirement effort decision, which is not (yet) constrained by an imposed requirement. At $t_{0}$ job seekers decide by themselves on the level of search which is optimal for them to implement. However, they may be aware about the legal obligation to search for a job and about the fact that the imposition of a search requirement is upcoming. They may thus build expectations about the future required search level. Nonetheless, since they do not yet know about their caseworker and have not received the full information about how the UI system will work, their expectations are marked by uncertainty.

By definition, we cannot formally test that $s_{0}$ is not systematically driven by expectations on the future requirement level. However, we can use the case of repeated spells to show that it is a reasonable assumption. For those who have already got in touch with the PES during a past unemployment spell, we know the requirement threshold of their previous unemployment spell. Figure 6a plots for these individuals the distribution of the current $s_{0}$ against the requirement $s_{r}$ of the previous spell. Although this past $s_{r}$ could allow job seekers to form an informed expectation on their future $s_{r}$, we see no systematic correlation. This supports the idea that individuals use the pre-requirement period to provide the effort level that is optimal from their individual perspective, without systematically taking into account expectations about the upcoming $s_{r}$. Also note that our baseline results do not change when we exclude job seekers with previous unemployment spells (c.f. section 6.3), which again supports that expectations are not a driving factor behind our treatment intensity.

In addition, we can provide descriptive evidence that $s_{0}$ has properties which are in line with the theoretical $s^{*}$. The choice of $s^{*}$ results from a trade-off between the job seeker's cost of effort $c^{\prime}\left(s_{1}\right)$ and his marginal benefit, caused an increase in the job arrival rate $\lambda^{\prime}\left(s_{1}\right)$ (c.f. section 2). Holding the marginal benefit of effort constant, individuals with a high effort cost will choose a relatively low level of $s^{*}$. At the same time, the cost of effort is also reflected in the job seeker's compliance choice under the requirement threshold. It was shown in section 2 that the job seeker's 
choice of compliance depends on a trade-off between the cost of the additional effort necessary to achieve compliance and the risk of benefit reductions imposed in the case of non-compliance. As a consequence, non-compliant job seekers who prefer to face a given probability of sanction will on average have a higher cost of effort than compliant job seekers. We can empirically test whether the job seeker's $s_{0}$ is correlated to her cost of effort as revealed by her compliance choice. Figure $6 \mathrm{~b}$ plots the share of non-compliant job seekers against $s_{0}$. It shows that $s_{0}$ is indeed highly correlated with the probability of being non-compliant at $t_{1} \cdot{ }^{18}$ This shows descriptively that $s_{0}$ reveals substantial information on the job seeker's cost of effort.

\section{[Insert Figure 6b]}

\subsection{Search Effort under Binding and Non-binding Requirements}

We conclude the descriptive analysis by providing descriptive evidence on the distribution of required and realized effort changes in our sample population. Figure 7 displays the distribution of the treatment intensity $\Delta_{s_{r}}=s_{r}-s_{0}$ in the categories that will be used in our empirical approach. The baseline category are job seekers with $\Delta_{s_{r}} \epsilon[-2,2]$, which are pooled into the status $\Delta_{s_{r}}=0$ under the assumption that very small $\Delta_{s_{r}}$ do not impose any strong changes in effort. ${ }^{19}$ It is visible that around one third of job seekers are within the range of $\Delta_{s_{r}} \epsilon[-2,2]$ and thus are not significantly affected by the presence of $s_{r}$. Around half of the job seekers face $\Delta_{s_{r}}>2$, which implies that they have to significantly increase their effort level relative to $s_{0}$ to achieve compliance. The requirement constraint is thus binding for them. Around $20 \%$ of job seekers can reduce their effort level relative to $s_{0}$ without becoming non-compliant $\left(\Delta_{s_{r}}<-2\right)$.

\section{[Insert Figure 7]}

How does the presence of $s_{r}$ affect the amount of provided search effort? Figure 8a plots the average change in search effort, $E\left(s_{1}-s_{0}\right)$, that occurred in each of the treatment bins. It shows that binding requirements are clearly associated with positive effort changes, as the average realized effort change increases with the treatment intensity $\Delta_{s_{r}}$. Strikingly, non-binding requirements $\left(\Delta_{s_{r}}<0\right)$ are associated with negative effort changes. This is not in line with the prediction from standard search theory, which implied that non-binding requirements do not affect search behavior at all (c.f. Figure 1).

Figure 8b confirms this picture: it shows that for job seekers with non-binding requirements, the average difference between the realized effort $s_{1}$ and the requirement $s_{r}$ ranges only between

\footnotetext{
${ }^{18} \mathrm{~A}$ job seeker is defined here as being non-compliant if the provided number of applicatiosn $s_{1}$ is less than $3 / 4$ of the required $s_{r}$.

${ }^{19}$ Our results are robust to alternative pooling choices, such as choosing the smaller baseline category $\Delta_{s_{r}} \epsilon[-1,1]$. Results are available upon request.
} 
one and two applications. This again suggests that while these job seeker's effort levels remain on average above $s_{r}$, they adjust their effort towards $s_{r}$. We will test in our econometric analysis whether these behavioral changes go along with changes in search outcomes.

Figure $8 \mathrm{~b}$ also shows that job seekers with strongly binding requirements submit on average less applications than required, which supports the theoretical predictions that compliance becomes less likely when the distance between $s_{r}$ and $s_{0}$ increases. In our econometric analysis, we will assess the causal effect of $\Delta_{s_{r}}$ on the job seeker's probability of non-compliance.

[Insert Figures 8a and 8b]

\section{Econometric Model and Identification}

Following our theoretical discussion, we want to identify how the difference between a job seeker's requirement threshold and her unconstrained search effort, $\Delta_{s_{r}}^{*}=s_{r}-s^{*}$, affects different job search outcomes. Based on the discussion in section 4.3, we use $s_{0}$ as a proxy for $s^{*}$. Our empirical approach therefore evaluates the effects of the treatment intensity $\Delta_{s_{r}}=s_{r}-s_{0}$. It is defined as the additional effort required at the beginning of the unemployment spell, beyond the provided pre-requirement effort level. This treatment intensity is positive in the case of a binding requirement threshold and negative in the case of a non-binding one, i.e. where the threshold is below the pre-requirement effort level.

The treatment intensity $\Delta_{s_{r}}$ results from a match between two endogenous variables: the job seeker's pre-requirement effort choice $s_{0}$ and his individual requirement level $s_{r}$ as assigned by the caseworker. In order to isolate the exogenous component of this match, we apply a set of fixed effects that controls for the direct effect of the job seeker's effort choice and the caseworker's requirement setting behavior on our outcomes of interest. We will argue that the remaining variation in the match between a job seeker's effort type and a caseworker's requirement setting behavior is random and can therefore be exploited to identify the causal effect of $\Delta_{s_{r}}$.

The empirical model applied for the estimations can be represented in the following baseline equation:

$$
y_{i}=\alpha+x_{i}^{\prime} \beta+\delta_{i}^{\Delta_{s_{r}}}+\gamma_{i}^{s_{0}}+\sigma_{i}^{s_{r}, c}+\pi_{c(i)}+\eta_{t}+u_{i}
$$

The main parameters of interest are $\delta^{\Delta_{s_{r}}}$, which measure how $\Delta_{s_{r}}$, the difference between the requirement $s_{r}$ and the pre-requirement search effort $s_{0}$, affects the outcome variable. In order to allow for non-linear effects of $\Delta_{s_{r}}$, a series of treatment intensity indicators is used, i.e. $\delta^{\Delta_{s_{r}}}$ represents dummy variables for bins in the distribution of $\Delta_{s_{r}}$. The baseline category pools job seekers with $\Delta_{s_{r}} \epsilon[-2,2]$, i.e. whose pre-requirement effort is very close to the requirement level. 
The distribution of the $\Delta_{s_{r}}$ bins is discussed in section $4 .^{20}$

\subsection{Identification Strategy}

We argue that we can isolate the causal effect of $\Delta_{s_{r}}$ by conditioning on the following set of fixed effects:

First, we control for the job seeker's pre-requirement effort choice $s_{0}$ through the vector of fixed effects $\gamma^{s_{0}}$. $\gamma^{s_{0}}$ features an indicator variable for each number of applications sent out in the month previous to the requirement. Thereby, it holds constant the direct impact of the individual's search "type". It can thus be seen as a measure of the individual search performance, driven by factors such as the intrinsic motivation, the assessment of labor market conditions and the experience with job search. In addition, $\eta_{t}$ controls for the time at which $s_{0}$ is measured. ${ }^{21}$

Second, we address the issue that requirement thresholds are allocated on a non-random basis by caseworkers at their first meeting with the job seeker. Our key argument is here that selection occurs with respect to the level of $s_{r}$, not with respect to its difference to the pre-requirement effort choice $s_{0}$. Requirement policies aim at ensuring a minimum effort level given the job seeker's labor market conditions. Caseworkers are asked to have this target in mind during the assignment process. According to a survey we performed, ${ }^{22}$ caseworkers indeed see the requirement policy as a means to ensure a certain level of search. They name the job seeker's labor market conditions as the most relevant determinants of this level. As a consequence, the influence that the caseworker's assessment of the job seeker's characteristics has on the requirement setting process should be fully reflected in the assigned requirement level. Holding this level constant therefore amounts to excluding the caseworker's assessment of the job seeker's characteristics from the variation in the treatment intensity $\Delta_{s_{r}}$. To achieve this, we introduce the variables $\sigma^{s_{r}, c}$ into our baseline equation. They include fixed effects for the difference between the individual's requirement level and the requirement of his caseworker's median case $\left(s_{r}-\operatorname{med}_{c}\left(s_{r}\right)\right)$. We thereby control for all systematic correlations between the individual's requirement threshold and the caseworker's assessment of the job seeker's labor market characteristics, relative to those of his median job seeker. ${ }^{23}$ Table 12 in Appendix A.2.1 contains summary statistics on the distribution of $\sigma^{s_{r}, c}$.

Finally, we account for the institutional environment of the requirement setting process. In

\footnotetext{
${ }^{20}$ Our results are robust to choosing different cutoff values for $\Delta_{s_{r}}$. Documentation is available upon request.

${ }^{21} \eta_{t}$ contains controls for the difference between $t_{0}$ and the start of formal unemployment as well as the difference between $t_{0}$ and the job seeker's availability for a new job. It also controls for the difference between the start of formal unemployment and the first caseworker meeting, to account for heterogeneity with respect to the arrival of the requirement threshold. Summary statistics on these variables are included in Appendix A.2, Table 13.

${ }^{22}$ Survey among 40 caseworkers in the canton of Bern

${ }^{23}$ Note that this specification is more flexible than introducing fixed effects for individual requirement levels, as it accounts for the fact that caseworkers can have different assessments of a "high" or "low" requirement. (For instance, a requirement of eight applications might be high for one caseworker and low for another caseworker.) However, our results are not substantially affected if we run a specification with fixed effects for $s_{r}$ levels.
} 
particular, we control for the fact that some caseworkers tend to assign higher average requirement thresholds than others. For instance, this might reflect local labor market conditions or caseworker "strictness". We account for such aspects by introducing caseworker fixed effects $\pi_{c}$ into our baseline equation. The introduction of caseworker fixed effects further excludes from our estimates all other policy choices which might be correlated with the requirement policy, such as monitoring and enforcement strictness or the emphasis placed on application quality. ${ }^{24}$

Note that our empirical approach explicitly omits variation stemming from the average caseworker policy. It thereby differs from approaches in previous literature which exploit that type of variation to generate random treatment assignment (e.g. Kling 2006; French and Song, 2014; Dahl et al., forthcoming). In the named studies, the treatment consists in the caseworker's or the judge's final decision on one specific issue (e.g. a criminal case). Therefore, random assignment of cases will generate variation only with respect to that specific treatment. In our setting, the caseworker's discretionary power is not limited to our treatment of interest, but rather extends to other policy instruments in the area of search assistance and search monitoring. We do not want these policy choices to affect the final outcome in a way which is correlated with the effects of $\Delta_{s_{r}}$. Therefore, we exploit variation conditional on caseworker fixed effects. This remainder variation reflects that different requirement setting preferences of one caseworker are arbitrarily matched to different pre-requirement effort types.

Thus, conditional on all the fixed effects contained in equation (1) and described above, the variation in $\Delta_{s_{r}}$ is driven by the arbitrariness of the match between the job seeker's unconstrained search behavior and the caseworker's requirement setting behavior. This arbitrariness is due to fixed assignment rules of "cases" to caseworkers in the PES. The most common assignment rules in the areas of the data sample are: by municipality, by occupation in the last job, by capacity (using a defined caseload formula) ${ }^{25}$. Therefore, the job seeker cannot select into a caseworker with a certain requirement setting behavior, nor can the caseworker choose job seekers with a certain pre-requirement effort. It is important to recall here that the direct impacts of the job seeker's "effort type" on the outcomes are held constant through the fixed effects contained in $\gamma^{s_{0}}$. The direct influence of a caseworker's behavior on the outcome is controlled by the caseworker fixed effect contained in $\pi^{c}$. And all systematic correlation between the caseworker's assessment of the job seeker's characteristics and the requirement threshold is accounted for by $\sigma^{s_{r}, c}$.

In our main specification, we also introduce a vector of job seeker characteristics $x_{i}$, which contains job seeker characteristics such as socio-demographics and labor market histories, seasonal

\footnotetext{
${ }^{24}$ Note that caseworker fixed effects also control for policy choices or impacts of the local economy at higher aggregate levels like the PES or the region.

${ }^{25}$ Source: inquiries at the national and some cantonal ministries of labor
} 
fixed effects and year fixed effects. ${ }^{26}$ Given that the specification without $x_{i}$ excludes all nonrandom components in $\Delta_{s_{r}}$, the introduction of $x_{i}$ should not change our estimates. This will prove to be the case.

\subsection{Further Estimation Details}

Equation (1) will be estimated by OLS for some of the outcomes of interest. We are also interested in the effects of the treatment $\Delta_{s_{r}}$ on the duration to job finding. To this purpose, we will estimate the job finding rate $\theta^{e}$, which is specified as a Proportional Hazard (PH):

$$
\ln \theta^{e}=\ln \lambda\left(t_{e}\right)+x_{i}^{\prime} \beta+\delta_{i}^{\Delta_{s_{r}}}+\gamma_{i}^{s_{0}}+\sigma_{i}^{s_{r}, c}+\pi_{c(i)}+\eta_{t}
$$

When estimating $\theta^{e}$, we model flexible duration dependence by using a step function

$$
\lambda\left(t_{e}\right)=\exp \left(\sum_{k}\left(\lambda\left(t_{e, k}\right) I_{k}(t)\right)\right.
$$

where $\mathrm{k}(=1, \ldots, 3)$ is a subscript for time intervals and $I_{k}(t)$ are time-varying dummy variables for subsequent intervals. As our focus is on the effect of required effort changes at the beginning of the spell, our main specification censors durations after six months. For this specification, we distinguish the following time intervals: 2-3 months, ${ }^{27} 3-4$ months and 4-6 months. In specifications where durations are censored after two years, we additionally distinguish the intervals 6-12 months and 12-24 months ${ }^{28}$. As we estimate a constant term, we normalize $\lambda\left(t_{e, 1}\right)$ to be 0 .

\subsection{Discussion of Identifying Assumptions}

We argued that conditional on the mentioned sets of identifying fixed effects, we can estimate the causal effect of $\Delta_{s_{r}}$ on the outcomes of interest. This relies on three central assumptions, which we discuss and test in the following.

Selection on Requirement Levels The baseline equation controls for the job seeker's assign-

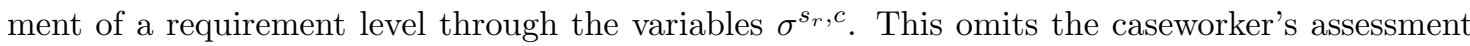
from the remaining variation in $\Delta_{s_{r}}$ if the caseworker expresses this assessment in the level of the requirement, not in its difference to the pre-requirement level $s_{0}$. Note that this assumption is

\footnotetext{
${ }^{26}$ Summary statistics on the variables contained in $x_{i}$ can be found in Table 14 .

${ }^{27}$ Note that job seekers with an unemployment duration of less than one month are excluded from our analysis because they are unaffected by the requirement regime (c.f. Appendix A.1.)

${ }^{28}$ The descriptive job finding hazard is plotted in Figure 19 in Appendix A.2
} 
not threatened by the fact that caseworkers observe $s_{0}$ at their first meeting with the job seeker. Caseworkers may take $s_{0}$ as a signal for the job seeker's characteristics or motivation, and adjust their choice of $s_{r}$ accordingly. As every job seeker provides such a signal, this mechanism is accounted for by the applied set of fixed effects. However, the assumption would be violated if caseworkers made their requirement assignment with the explicit aim of generating a certain $\Delta_{s_{r}}$. In this case, the caseworker's assessment of the job seeker would not be captured by $\sigma^{s_{r}, c}$ . As mentioned in the previous subsection, anecdotal and survey evidence strongly suggest that caseworkers aim at imposing a certain minimum search level on the job seeker. This claim is supported by columns (2) and (3) Table 1, which show that the impact of the job seeker's main observable characteristics (Gender, Education, Sector and Age) on the requirement threshold is not affected when $s_{0}$ is accounted for through fixed effects. $s_{0}$ does thus not provide the average caseworker with any information that affects the determinants of his requirement assignment. In addition, Figure 9 shows that the residuals predicted from a regression of $s_{r}$ on caseworker fixed effects and the vector $x$ is not systematically related to $s_{0} \cdot{ }^{29}$

[Insert Figure 9]

Absence of Confounding Policy Choices Second, we assume that in our identifying framework, the effect of $\Delta_{s_{r}}$ is not driven by other correlated policy choices. While we control for the caseworker's average policy strategy through the caseworker effects, a caseworker might implement other job seeker-specific policies that correlate with $\Delta_{s_{r}}$ and a given outcome. In Table 2, we provide evidence that $\Delta_{s_{r}}$ is unrelated to other policy choices by the caseworker: given our econometric framework, there is no significant effect of the treatment on the probability that an "early" second meeting ${ }^{30}$ is scheduled, which is a proxy for the meeting intensity to which the job seeker is assigned. There is also no significant effect on the probability that a benefit sanction that is unrelated to the compliance with the requirement is imposed during the first two months of the job seeker's spell.

[Insert Table 2]

\section{Exogenous Match between Job Seeker Types and Caseworker Requirement Setting}

A third implication of our exogeneity assumption concerns the mapping according to which the caseworker assigns requirement thresholds to the job seeker based on their characteristics. We argue that the match between the caseworker's requirement setting process and the job seeker's search type is random conditional on the set of identifying fixed effects. In other words, we assume that

\footnotetext{
${ }^{29}$ The residual is estimated as $\hat{\varepsilon}=\hat{s}_{r}-x^{\prime} \hat{\beta}-\hat{\pi}^{c}$

${ }^{30}$ Defined as a meeting that is scheduled less than three weeks after the first meeting.
} 
a job seeker's type does not systematically affect how the caseworker distributes the requirements among her job seekers. One central feature of a caseworker's requirement setting criteria is the influence that a job seeker's characteristics have on her assigned requirement. In order to measure this influence, we run for each caseworker a regression that links a job seeker's requirement to her observable characteristics. We predict the resulting requirement as $\hat{s}_{r, c}$ and compute its standard deviation as a measure of its spread. We show in Figure 10 that this standard deviation is unrelated to the average $s_{0}$ of job seekers that are assigned to a given caseworker. There is thus no systematic relation between the average job seeker type assigned to a caseworker and the degree to which job seeker characteristics map into the caseworker's requirement decision.

[Insert Figure 10]

In addition to the discussed tests, the regression results presented in section 6 support the argument that the variation in $\Delta_{s_{r}}$ is exogenous conditional on the identifying fixed effects $\gamma^{s_{0}}$, $\sigma^{s_{r}, c}$ and $\pi^{c}$. First, the introduction of the vector $x_{i}$ does not change the results on the treatment effects. As $x_{i}$ contains those factors which caseworkers name as essential determinants of their requirement setting decision (e.g. occupation, education, age), we would expect this if our baseline specification suffered from omitted variables. As an additional robustness test, we introduce an interaction between $s_{0}$ and different sets of observable labor market characteristics. This should generate additional information on the job seeker's unobserved characteristics, as submitting a given level of $s_{0}$ might reveal a higher motivation in some occupations than in others. Again, our results are not affected by the introduction of these supplemental variables (c.f. Table 10).

\section{Estimation Results}

\subsection{Compliance with the Requirement}

Our theoretical discussion showed that job seekers with a high treatment intensity $\Delta_{s_{r}}$ face higher costs of compliance, which makes it relatively more attractive for them to submit less applications than required. In Table 3, we test this hypothesis. Column (1) estimates the impact of $\Delta_{s_{r}}$ on the probability of non-compliance ${ }^{31}$. Binding requirements increase this probability substantially: for instance, job seekers in the two highest treatment bins, who have to submit applications more than they did in the pre-requirement period, are about 4 percentage points more likely not to comply with the requirement. Given that the mean non-compliance probability is around $12 \%$, this effect is substantial. It confirms the theoretical prediction that non-compliance will systematically occur

\footnotetext{
${ }^{31}$ measured as $s_{1} / s_{r}<3 / 4$
} 
among job seekers who find compliance difficult to achieve.

Column (2) shows that this translates into an increased non-compliance detection rate: for instance, job seekers with $\Delta_{s_{r}} \epsilon[7,8]$ face am increase in their probability of being registered as non-compliant within the first two months of unemployment ${ }^{32}$ by 3 percentage points, compared to job seekers in the baseline category $\left(\Delta_{s_{r}} \approx 0\right)$. This is again substantial compared to the average warning probability of $9 \%$. The effect on a realized benefit sanction is quantitatively similar, as shown in column (3).

The results of column (2) and (3) are illustrated in Figure 11. It shows that the effect of binding requirements on non-compliance detection and sanction enforcement are nearly linear. Job seekers with non-binding requirements have the same probability of non-compliance as job seekers in the baseline category. This is in line with the theoretical idea that for all individuals with $\Delta_{s_{r}} \leqslant 0$, compliance induces no cost. The treatment intensity is therefore irrelevant for job seekers with non-binding requirements. Finally, recall from Table 2 that there was no effect of $\Delta_{s_{r}}$ on the "Placbo outcome" for an unrelated benefit sanction. This check confirms the interpretation that the effects on non-compliance with search requirements are driven by an exogenously determined $\Delta_{s_{r}}$.

The results from Table 3 evoke two conclusions: first, individuals translate increased compliance cost into their actual compliance behavior. Thus, policy makers should be aware that non-compliance and increased sanction rates are a side effect and potential cost of high search requirements. Second, increased sanction rates are an additional channel through which the treatment $\Delta_{s_{r}}$ can affect the exit from unemployment. We do not estimate a multiple-step framework that is able to systematically assess this channel. However, we will present a robustness check in which we introduce the incidence of a benefit sanction into our final outcome equation (section $6.3)$.

[Insert Table 3]

\subsection{Job Finding and Job Stability}

\subsubsection{Effect on Job Finding}

We estimate the impacts of the treatment intensity $\Delta_{s_{r}}$ on job finding in a duration framework, which models the exit from unemployment to a job as a flexible proportional hazard $(\mathrm{PH}) .{ }^{33} \mathrm{In}$ our main regressions, we censor durations after six months of unemployment. The reason is that

\footnotetext{
${ }^{32}$ We choose such a short time interval to avoid that dynamic selection drives our results.

${ }^{33}$ We also estimated OLS regressions on the linear probability of job finding, as a robustness check and for the assessment of job stability effects. In Table 9, we report the effects on the probability of job finding within 6 months and decompose it into stable and unstable jobs. Other OLS results on job finding are available upon request.
} 
$\Delta_{s_{r}}$ is expected to generate behavioral changes in search effort predominantly at the beginning of the spell. We therefore focus on the effect of $\Delta_{s_{r}}$ on the duration of unemployment and the probability of job finding within the first six months after registration at the PES. $45 \%$ of the sample population exits unemployment within these six months.

Columns (1) to (3) of Table 4 provide treatment effects for the main regression. They evaluate the impact of $\Delta_{s_{r}}$ with respect to the baseline category $\Delta_{s_{r}} \epsilon[-2,2] \approx 0$. Columns (1) and (2) display coefficients on the job finding hazard, censored at 6 months. Column (1) shows results for equation (1), excluding the vector of individual covariates $x_{i}$. In column (2), $x_{i}$. The coefficients from the two columns are not statistically different from each other. They both show that job seekers who have to increase their search effort due to the presence of the search requirement substantially increase job finding. For instance, job seekers who have to write 3 or 4 applications more than in absence of the requirement raise their job finding hazard by $14 \%$ (=exp(.132)-1), compared to the baseline group with $\Delta_{s_{r}} \epsilon[-2,2] \approx 0$. Column $(3)$ reports the corresponding marginal effects, ${ }^{34}$ which measure the effect of the treatment on the probability of job finding within six months. The effect of $\Delta_{s_{r}} \epsilon[3,4]$ on this probability is 2 p.p and increases up to $4(5)$ p.p for job seekers with $\Delta_{s_{r}} \epsilon[7,8]\left(\Delta_{s_{r}}>8\right)$. If we assume the effect of binding requirements to be linear, one additional required monthly application increases the probability of job finding within six months by .5 p.p. The regression does not report any significant effects on job seekers with non-binding requirements, i.e. with $\Delta_{s_{r}}<0$.

In Appendix A.2, Figure 18, we graphically illustrate coefficients also for the set of fixed effects $\gamma^{s_{0}}$ and $\sigma^{s_{r}, c}$. These are as expected: an increase in $s_{0}$ is associated with an increased job finding rate. An increase in $s_{r}-\operatorname{med}_{c}\left(s_{r}\right)$, which means that the caseworker assigned the individual a higher requirement relative to his median case, is associated with a decreased job finding rate. These results provide some further empirical evidence that $\gamma^{s_{0}}$ and $\sigma^{s_{r}, c}$ capture important aspects of the individual's search ability such as revealed by the individual $\left(s_{0}\right)$ or assessed by the caseworker $\left(s_{r}-\operatorname{med}_{c}\left(s_{r}\right)\right)$.

\section{[Insert Table 4 and Figure 13]}

In columns (4) to (7), we present results from regressions with alternative censoring dates. Column (4), which reports coefficients on the hazard censored after 3 months, and column (5), which shows the corresponding marginal effects, confirm that the effects of a required search effort are strongest at the very beginning of the unemployment spell. Strikingly, we observe here a negative effect of non-binding requirements on early job finding. Job seekers who receive a signal

\footnotetext{
${ }^{34}$ Marginal effects of duration models are obtained by taking the difference of a predicted survivor rate under the treatment and a counterfactual survivor rate which imposes the treatment to equal zero. The change in survivors is averaged with respect to the individual characteristics in the sample population and gives the average marginal effect on the respective job finding probability.
} 
that their search effort was higher than the effort level considered as sufficient by the caseworker reduce their early exit rate. This finding contradicts standard job search theory, which predicts that only job seekers with a positive treatment intensity change their behavior in response to the threshold. Therefore, requirement thresholds not only seem to operate as a binding or non-binding constraint, but also as signals, which also affect behavior when the constraint is non-binding. We will further discuss these effects in relation with the effects of non-binding requirements on job stability. Naturally, a treatment that occurs at the beginning of the unemployment spell can have impacts on the entire course of the unemployment spell. Columns (6) and (7) show that the effect of binding requirements averaged over the entire observation period remains positive and significant.

Figures 13a graphically illustrates the effects of $\Delta_{s_{r}}$ on the job finding hazard when choosing different censoring dates. Figure 13b illustrates effects on the probability of job finding within the censoring period (marginal effect). They show that the effect of binding requirements has a concave shape, indicating that there are decreasing returns to required effort increases.

\subsubsection{Heterogeneous Effects}

We next discuss how the effects of $\Delta_{s_{r}}$ on job finding differ according to both the job seeker's characteristics and the labor demand situation. All durations are now censored after 6 months of unemployment, as this makes the results comparable to our baseline estimates in Table $4 .{ }^{35}$

Table 5 presents heterogeneity with respect to gender and education of the job seeker. Figure 14 graphically illustrates these results. Columns (1) and (2) and Figure 14 (a) show that the evoked "signalling effect" is stronger for male job seekers, whose job finding propensity within the first six months decreases significantly in response to a non-binding requirement. We further observe that male job seekers increase their job finding rate significantly less in response to a required effort increase than female job seekers. Female job seekers react stronger to the incentive for effort increases: for example, a binding search requirement of $\Delta_{s_{r}} \epsilon[5,6]$ increases the job finding hazard of female job seekers by around $30 \%$, compared to an increase of $11 \%$ for male job seekers.

Columns (3) to (5) and Figure 14 (b) further illustrate that results are driven by job seekers with low educational attainment. Job finding hazards of unlearned job seekers respond the strongest to required effort increases; in turn, we find few significant effects on job finding hazards of job seekers with high school diploma and above. One possible explanation is that job seekers with a higher degree of education and specialization are bounded in their quantitative search effort by the availability of suitable offers. Further, the quality of applications might be of higher importance for this subgroup of job seekers, which is why search requirements that target the quantity of

\footnotetext{
${ }^{35}$ Marginal Effects for the hazard coefficients are omitted to save space and available upon request.
} 
applications are less effective.

[Insert Table 5 and Figure 14]

Table 6 and Figure 15 decompose the effects by occupational degrees. Columns (1) to (3) and Figure 15 (a) show that average effects are largely driven by job seekers in the low service sector, i.e. the cleaning and restaurant sector. Blue collar workers show no reaction. ${ }^{36}$ In Columns (4) to (5) and Figure 15 (b), it can be seen that workers who had a support function in their previous employment react more than job seekers who had a professional or management function. Again, this supports the central result that required changes in the quantity of effort lead to changes in outcomes mainly for job seekers with lower qualification.

[Insert Table 6 and Figure 15]

As a final heterogeneity analysis, Table 7 and Figure 16 present results for subgroups that face a relatively large vs. small labor demand. We use vacancy rates as proxies for the labor demand that the job seeker faces. Vacancy rates are calculated as the ration of posted vacancies over job seekers on a month-region basis. ${ }^{37}$ They are assigned to the job seeker on the basis on her month and place of registration at the PES. "Low", "medium" and "high" vacancy rates are in relative terms, i.e. we divide the distribution of vacancy rates by 3 to assign job seekers to one of these categories.

We observe that effects are largest for job seekers who face a relatively high vacancy rate and nearly absent if job seekers who face a relatively low vacancy rate. Note that Switzerland is generally a country where unemployment is relatively low. In addition, there was no true economic downturn during our sample period. This implies that search requirements might have a lower effect in settings in which labor demand is truly stagnating.

\section{[Insert Table 7]}

\subsubsection{Job Stability}

One fundamental question is whether the substantial effects on job finding come at the cost of worsened job quality. We have no access to characteristics of the job match, but we observe in the UI data when a job seeker re-enters unemployment. As a consequence, we are able to estimate the causal effect of $\Delta_{s_{r}}$ on the probability of recurrence to unemployment within (6/12) months

\footnotetext{
${ }^{36}$ The occupational patterns still hold when their interaction with the job seeker's gender is accounted for (results available upon request).

${ }^{37}$ We distinguish by local labor market regions ("MS-regions") of which 102 exist in Switzerland.
} 
after job finding. ${ }^{38}$ Table 8 presents coefficients of $\Delta_{s_{r}}$ on these outcomes. Column (1) reveals $a$ substantial negative effect of binding requirements on job stability. An increase in $\Delta_{s_{r}}$ substantially increases the probability that any job seeker enters a job and re-enters unemployment within six months. If we assume the effect to be linear, the effect size is at the order of .7 percentage points per additional required application (on an outcome mean of 13.8\%). This suggests that binding requirements induce job seekers to apply more frequently to either very temporary jobs or jobs that prove to be a bad match. Interestingly, these effects disappear when we look at recurrence within 12 months (column (3)). This suggests that in absence of binding requirements, job seekers would have entered more stable jobs, which would however not have been permanent jobs either. It is also interesting to see that the effects of non-binding requirements are nearly symmetric: job seekers who receive a requirement that allows reducing search effort with respect to $s_{0}$ appear to reduce the quantity and increase the quality of job applications. This significantly improves job match stability.

Columns (2) and (4) present the same regressions for the subsample of unlearned job seekers, which is a group whose job finding rate is particularly affected by $\Delta_{s_{r}}$. Indeed, also the probability of recurrence within 6 month reacts particularly for these job seekers.

\section{[Insert Table 8]}

These results raise the question whether the effects on job finding identified in section 6.2.1 are fully driven by exits to unstable jobs. We assess this issue in Table 9, which decomposes the effects of $\Delta_{s_{r}}$ on the probability of exiting to a job within 6 months into exits to permanent and non-permanent jobs. Column (1) shows estimates on the linear probability of job finding within six months. In column (2), the outcome is coded as one if a job seeker finds a job within six months and recurs to unemployment within the following six months. The effect of $\Delta_{s_{r}}$ is substantial and suggests that requirement-induced job matches are non-permanent ones. Column (3) confirms this picture: binding requirements have no effect at all on the probability of exiting to a job that lasts more than six months. By contrast, non-binding requirements have a positive effect on this probability. It appears that job seekers who decrease their search effort after receiving the requirement do so by applying less to temporary or bad-quality jobs. Through this channel, they have a higher chance of finding a permanent job within the first six months of their unemployment spell.

Given the presented results, we identify a central policy trade-off concerning the job seeker's short term outcomes: requirement-induced search effort can shorten the duration of unemployment,

\footnotetext{
${ }^{38}$ Note that as we observe entries to unemployment until August 2014 and our sample covers entries until December 2012, some of our observations are right censored. This should not affect our results, as this censoring is unaffected by the treatment.
} 
but only at the cost of job match stability. Given our data setting, we cannot answer the longterm welfare question whether increased exits to temporary jobs improve the individual's long-run employment outcomes (e.g. through a stepping-stone mechanism) or not. We leave this question for future research.

\section{[Insert Table 9]}

\subsection{Robustness Checks}

In a final step, we present a set of additional robustness checks. We use the main regression on the job finding hazard with durations censored after six months of unemployment to run these checks.

We first want to further test that our econometric specification indeed identifies the causal effect of required effort changes. In Table 10, column (1) recalls our baseline estimates. Columns (2) and (3) test whether the indicators $\gamma^{s_{0}}$ sufficiently control for the job seeker's effort type. A concern might be is that one level of $s_{0}$ can reveal different unobserved characteristics, depending on the job seeker's labor market situation: one level of $s_{0}$ could reveal a high or low intrinsic motivation, depending on the effort which is "standard" for the job seeker's gender or education group. If this concern is irrelevant, results should be unchanged when we interact $\gamma^{s_{0}}$ with labor market characteristics. In column (2) (column (3)), we introduce an interaction between $\gamma^{s_{0}}$ and a vector of educational categories (a gender dummy) into the baseline regression. Results are unaffected by this. Column (4) presents a tentative check on the role of benefit sanctions. Previous research, e.g. by Lalive et al. (2005), Abbring et al. (2005), Arni et al. (2013) and Van Ours and Van der Klaauw (2014), shows that benefit sanctions substantially increase job finding. As the treatment intensity $\Delta_{s_{r}}$ increases non-compliance and the incidence of benefit sanctions, it is possible that job search behavior reacts above all to the intermediate outcome of imposed benefit sanctions. Like in these studies, the regression whose results are reported in column (4) allows the job finding hazard to shift when job seekers receive a warning on non-compliance detection and when a sanction is imposed. These events are quite obviously endogenous to the treatment and thus do not represent good control variables. Nonetheless, they show that sanctions are not the driving factor behind our main results, as point estimates are only slightly and not statistically significantly decreased. ${ }^{39}$

Table 11 provides additional robustness checks by presenting results that exclude potentially sensitive subgroups. Column (1) recalls our baseline estimates. Column (2) shows results estimated only with job seekers for whom requirement levels were not imputed (91.8\%). Column (3)

\footnotetext{
${ }^{39}$ Note that in this context, we are unable to check for the role of the "ex-ante" threat effect of an increased sanction probability.
} 
reports estimates only for the homogeneous group of job seekers for whom $s_{0}$ refers to the month previous to registration at the PES (42.9\%; see section A.1.2 in the Appendix for the timing of the pre-requirement period $t_{0}$.) Finally, estimates in column (4) only contain job seekers who did not have another unemployment spell in the two years previous to entering their current spell (78.5\%). These job seekers have never -or not during a considerable amount of time- entered in contact with the requirement regime (c.f. issues raised in section 4.3). For none of these subgroups, the estimates are significantly different from the baseline results.

\section{Discussion and Conclusion}

Our analysis is the first to identify the causal effect of individual-level effort changes that are imposed by job search requirements. Guided by search theory, we focus on assessing the effects of the incremental effort that is necessary to comply with the requirement, beyond the job seeker's unconstrained effort choice. Our results show that binding job search requirements substantially affect the individual's effort choice and also the resulting job finding outcome. Thus, they do not generate pure "spam" applications solely used to comply with the rules, but are actually effective for job finding, in particular at early stages of the unemployment spell. In this sense, individual search requirements are a policy instrument that may help to counter the issue of effort under-provision due to moral hazard.

However, some additional findings should be taken into account for policy design. First, we show that in line with theoretical predictions, the elasticity of search effort to the requirement is imperfect: non-compliance rates react substantially to the individual treatment exposure. This suggests that job seekers may find it beneficial to take the risk of benefit sanctions when the required change in search behavior induces large search costs. Coherently, our results show that the probability of receiving a benefit sanction reacts remarkably to the required increase in effort. Secondly, the effects of job search steering by requirements are clearly heterogeneous. Besides substantial gender differences in effort reactions, the estimation results show that the imposition of a requirement mostly exerts pressure on individuals with lower qualifications and in lower-skilled service occupations, whereas the instrument barely shows any impact on higher-skilled job seekers. In addition, requirements induce hardly any effects on job finding when the vacancy rates are low.

Thirdly, we show that the positive effects on job finding largely come at the cost of job stability. The requirement-induced job finding is strongly driven by the take-up of more temporary jobs. This evokes a quantity-quality trade-off: binding requirements help individuals to return faster to the labor market, but they bear the risk of pushing weaker job seekers into unstable employment conditions. In the worst case, this may promote "revolving doors" careers through the repeated recurrence to unemployment, while in the better case the temporary jobs found could serve as 
stepping stones. At this stage, we cannot yet assess the long-term welfare implications of required search effort changes on individual employment careers. We leave this to future research.

Finally, our results provide the surprising finding that non-binding requirements also affect job search outcomes, which is not in line with the predictions of standard job search theory. After receiving a search requirement, job seekers move their realized search effort towards the requirement threshold, also when their unconstrained search level was significantly higher. This reduction in quantitative search effort negatively affects job finding at early stages of the unemployment spell and positively affects job match stability. Thus, search requirements not only appear to operate as enforced constraints, but also as reference points that signal the "right" search intensity and thereby provoke a shift from application quantity to quality. This reference point mechanism holds particular relevance for policy design in terms of individual targeting of the requirement.

This paper contributes to the generally scarce empirical evidence on the reaction of individual effort to incentives provided by social insurance and welfare policies. Such detailed insights into behavioral mechanisms are essential for policy targeting as well as for optimal UI design. In traditional theoretical analyses of the optimal UI problem, benefit levels are the social planner's central instrument to trade off moral hazard and insurance concerns, subject to budget constraints (Hopenhayn and Nicolini 1997). Pavoni and Violante (2007) show that introducing job search monitoring as an additional instrument into UI can be welfare improving. The intuition behind this central result is that policy makers can afford to set higher benefit levels when monitoring counteracts the insurance-incentive trade-off and guarantees that search effort does not become sub-optimally low. Our findings deliver evidence on how requirements and monitoring affect search outcomes in a real-world context with imperfect compliance and imperfect information. This evidence provides an important base for future research that empirically assesses the welfare consequences of policy mixes with effort enforcement. The increased availability of large-scale data which combine behavioral information with the quality of registers will allow further developing these avenues of research. 


\section{$8 \quad$ Figures and Tables}

Figure 3: Distribution of $s_{0}$

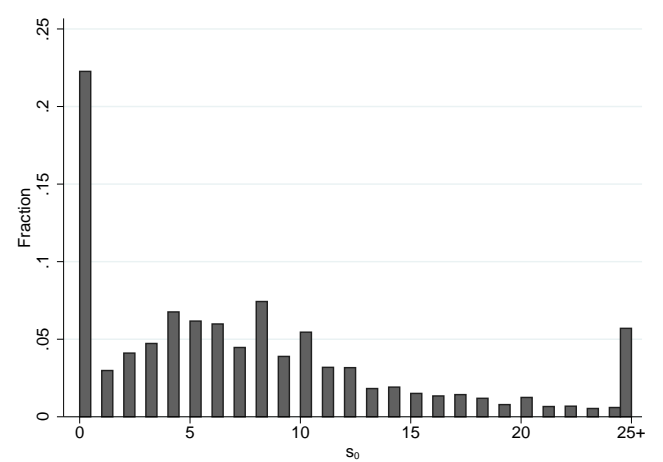

Figure 4

(a) Sample Distribution of $s_{r}$

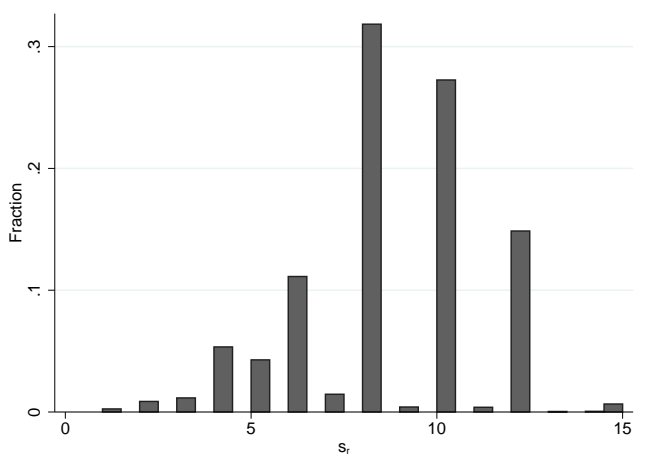

(c) $E\left(s_{r}\right)_{\text {Caseworker }}-E\left(s_{r}\right)_{P E S}$

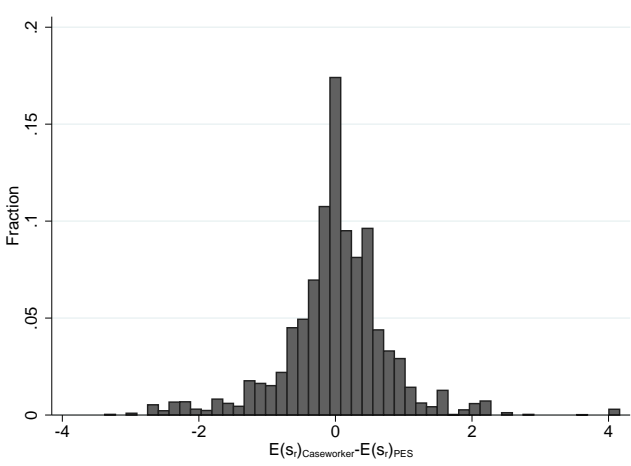

(b) Distribution of $E\left(s_{r}\right)_{P E S}$

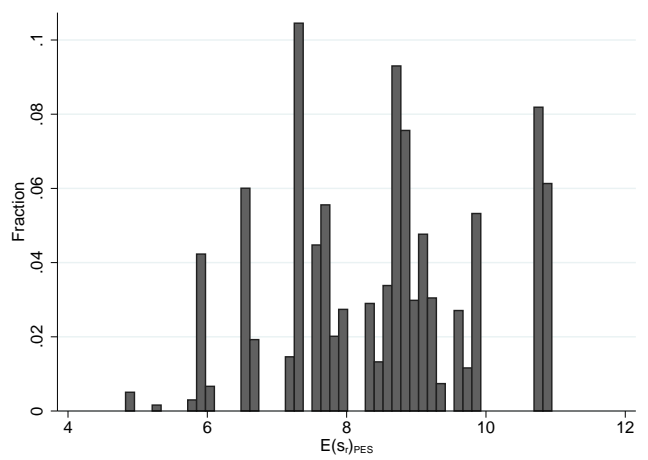

(d) Caseworker "Requirement Portfolio"

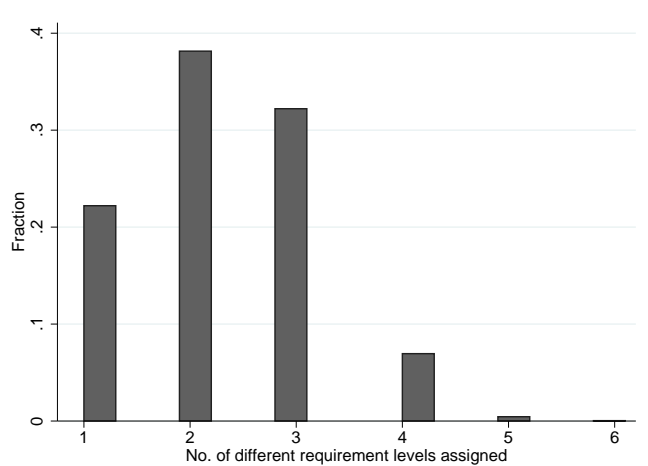

Graphs (b) to (d) are weighted by the number of job seekers. In (a) and (b), $E\left(s_{r}\right)_{P E S}$ denotes the average requirement

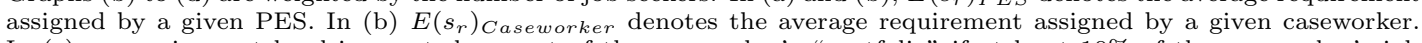
In (c), a requirement level is counted as part of the caseworker's "portfolio" if at least $10 \%$ of the caseworker's job seekers receive that requirement threshold. 
Figure 5: Distribution of $s_{1} \mid s_{r}$

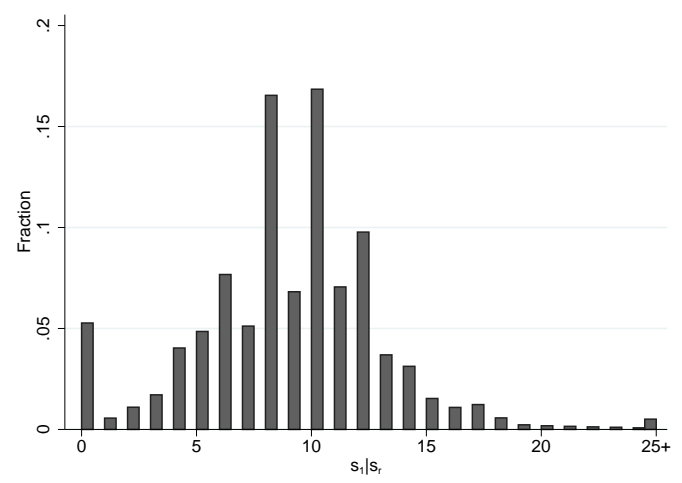

Table 1: Influence of Job Seeker Characteristics on $s_{r}$ and $s_{0}$

\begin{tabular}{lccc}
\hline \hline & $(1)$ & $(2)$ & $(3)$ \\
& $\mathrm{s} 0$ & $\mathrm{sr}$ & $\mathrm{sr} / \mathrm{s} 0$ \\
\hline Female & $0.349^{* * *}$ & $-0.068^{* * *}$ & $-0.066^{* * *}$ \\
& $(0.069)$ & $(0.020)$ & $(0.020)$ \\
Low Education & $-0.560^{* * *}$ & $0.085^{* * *}$ & $0.095^{* * *}$ \\
& $(0.123)$ & $(0.021)$ & $(0.020)$ \\
High Education & 0.071 & $-0.589^{* * *}$ & $-0.577^{* * *}$ \\
& $(0.122)$ & $(0.039)$ & $(0.039)$ \\
Age 35-45 & & & $-0.299^{* * *}$ \\
& $0.676^{* * *}$ & $-0.298^{* * *}$ & $(0.023)$ \\
Age $>45$ & $(0.063)$ & $(0.022)$ & $-0.557^{* * *}$ \\
& & & $(0.033)$ \\
Service Sector Low & $0.943^{* * *}$ & $-0.560^{* * *}$ & 0.035 \\
& $(0.080)$ & $(0.033)$ & $(0.034)$ \\
Service Sector High & $0.698^{* * *}$ & 0.043 & \\
& $(0.110)$ & $(0.035)$ & $0.054^{*}$ \\
Professional+ Function & $0.927^{* * *}$ & $0.066^{* *}$ & $(0.028)$ \\
FE & $(0.089)$ & $(0.028)$ & $-0.171^{* * *}$ \\
Outcome Mean & -0.037 & $-0.175^{* * *}$ & $(0.024)$ \\
\hline \hline
\end{tabular}

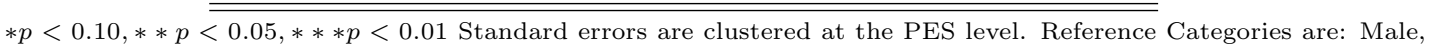
No Education/Unlearned, Age $<35$, Blue Collar Sector, Support Function. 
Figure 6: Properties of $s_{0}$

(a) $s_{0}$ plotted over $s_{r}$ of previous spell

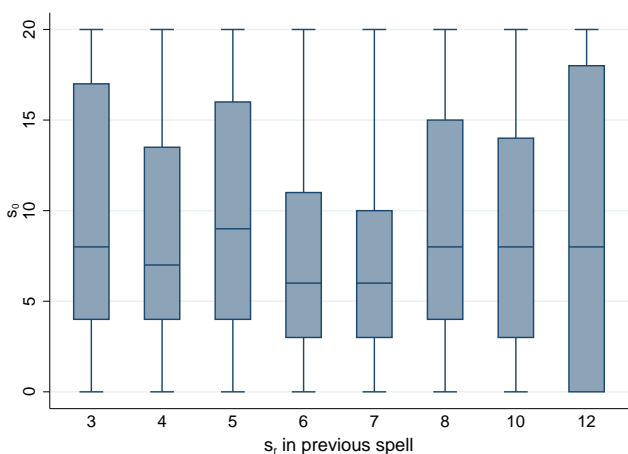

$\mathrm{N}=12830$. Observations with a previous requirement that affects less than $1 \%$ of repeated spells are excluded. Job seekers with $s_{0}>20$ are pooled into $s_{0}=20$ (b) Share of non-compliers by $s_{0}$

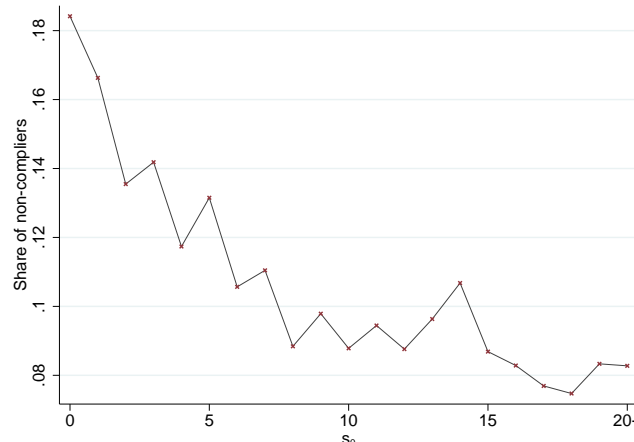

A job seeker is defined as non-compliant if $s_{1} / s_{r}<3 / 4$

Figure 7: Distribution of $\Delta_{s_{r}}$

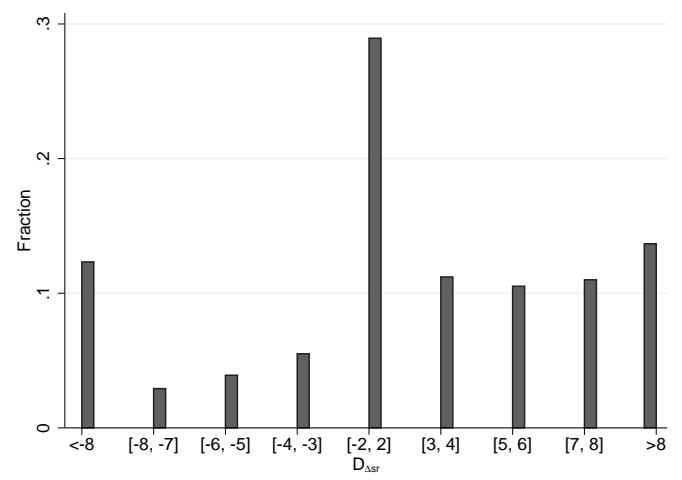


Figure 8: Required and Realized Effort Changes

(a) $E\left(s_{1}-s_{0}\right) \mid \Delta s_{r}$

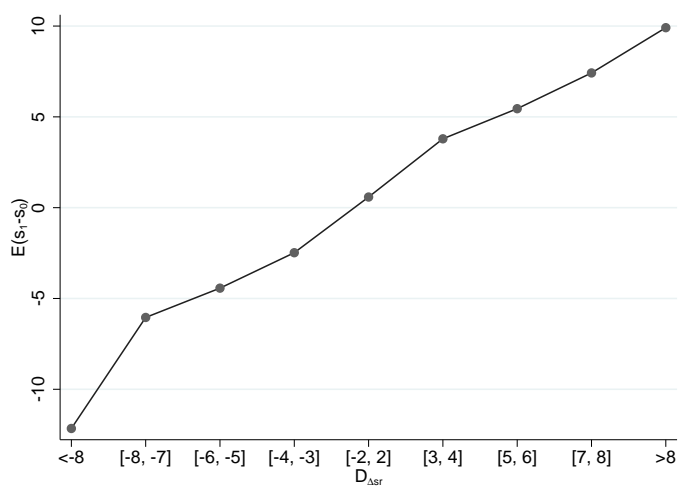

(b) $E\left(s_{1}-s_{r}\right) \mid \Delta s_{r}$

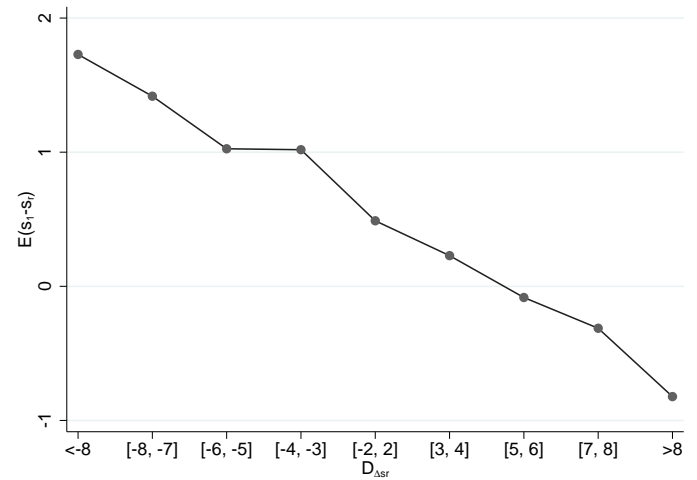

Figure 9: Residuals of Requirement Regression $\left(\hat{\varepsilon}=\hat{s}_{r}-x^{\prime} \hat{\beta}-\hat{\pi}_{c}\right)$ Plotted over $s_{0}$

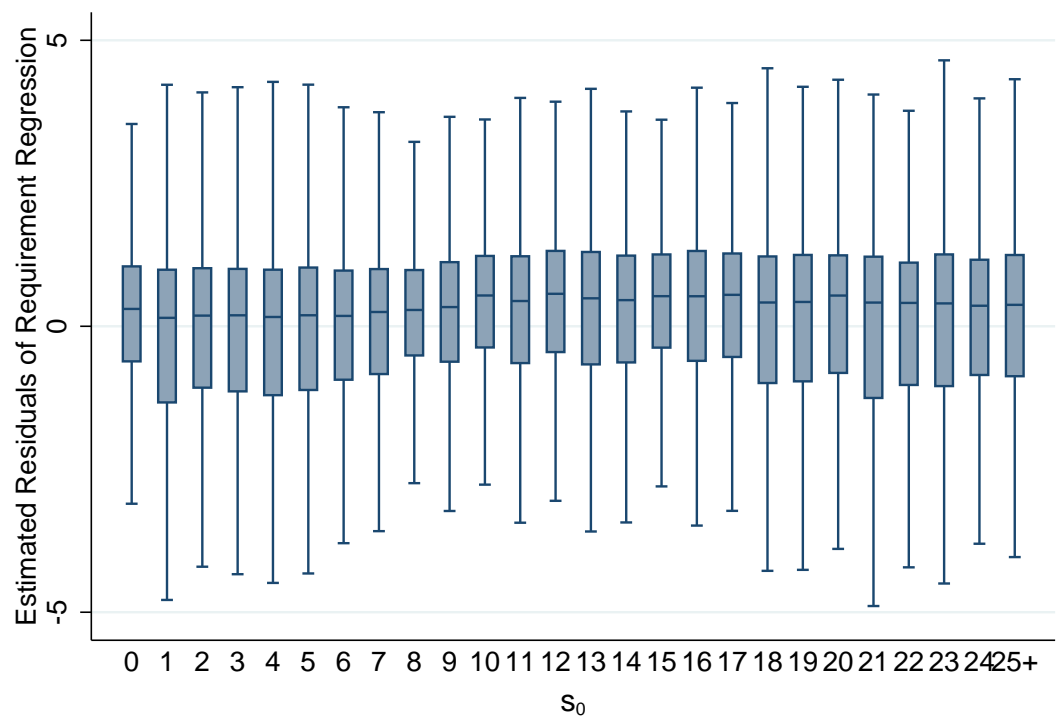

Note: excludes outside values 
Table 2: "Placebo Policy" Regressions

\begin{tabular}{|c|c|c|}
\hline & $\begin{array}{c}(1) \\
\text { Early Second Meeting }\end{array}$ & $\begin{array}{c} \\
\text { Unrelated Sanction (2 Months) }\end{array}$ \\
\hline$\Delta_{s_{r}}<-8$ & $\begin{array}{c}0.012 \\
(0.016)\end{array}$ & $\begin{array}{l}-0.002 \\
(0.007)\end{array}$ \\
\hline$\Delta_{s_{r}} \in[-8,-7]$ & $\begin{array}{l}-0.008 \\
(0.013)\end{array}$ & $\begin{array}{c}0.002 \\
(0.006)\end{array}$ \\
\hline$\Delta_{s_{r}} \epsilon[-6,-5]$ & $\begin{array}{c}0.006 \\
(0.010)\end{array}$ & $\begin{array}{l}-0.002 \\
(0.004)\end{array}$ \\
\hline$\Delta_{s_{r}} \epsilon[-4,-3]$ & $\begin{array}{c}0.005 \\
(0.008)\end{array}$ & $\begin{array}{c}0.002 \\
(0.003)\end{array}$ \\
\hline$\Delta_{s_{r}} \epsilon[3,4]$ & $\begin{array}{c}0.001 \\
(0.007)\end{array}$ & $\begin{array}{c}0.001 \\
(0.004)\end{array}$ \\
\hline$\Delta_{s_{r}} \epsilon[5,6]$ & $\begin{array}{l}-0.000 \\
(0.010)\end{array}$ & $\begin{array}{c}0.002 \\
(0.005)\end{array}$ \\
\hline$\Delta_{s_{r}} \epsilon[7,8]$ & $\begin{array}{l}-0.008 \\
(0.012)\end{array}$ & $\begin{array}{c}0.004 \\
(0.006)\end{array}$ \\
\hline$\Delta_{s_{r}}>8$ & $\begin{array}{l}-0.010 \\
(0.016)\end{array}$ & $\begin{array}{c}0.013 \\
(0.008)\end{array}$ \\
\hline $\begin{array}{l}\text { Outcome Mean } \\
\mathrm{N}\end{array}$ & $\begin{array}{l}0.164 \\
76404\end{array}$ & $\begin{array}{l}0.045 \\
76404\end{array}$ \\
\hline
\end{tabular}

$* p<0.10, * * p<0.05, * * * p<0.01$. Standard errors are clustered at the caseworker level. The reference category is $\Delta_{s_{r}} \epsilon[-2,2]$. All regressions estimate equation 1 using OLS. They include all identifying fixed effects (discussed in section 5) and all covariates, which control for gender, age, immigration status, civil status, household size, education, employment and unemployment history, quarter and year of UE entry. Summary statistics on all explanatory variables can be found in Appendix A.2. "Early Second Meeting" is coded as one if the difference between the first caseworker meeting and the second scheduled meeting is less than three weeks. "Unrelated Sanction (2 Months)" is coded as one if the job seeker receives a sanction for delayed appearance or absence at a caseworker meeting during the first two months of UE. 
Figure 10: $\hat{s}_{r, c}$ plotted over $\bar{s}_{0, c}$

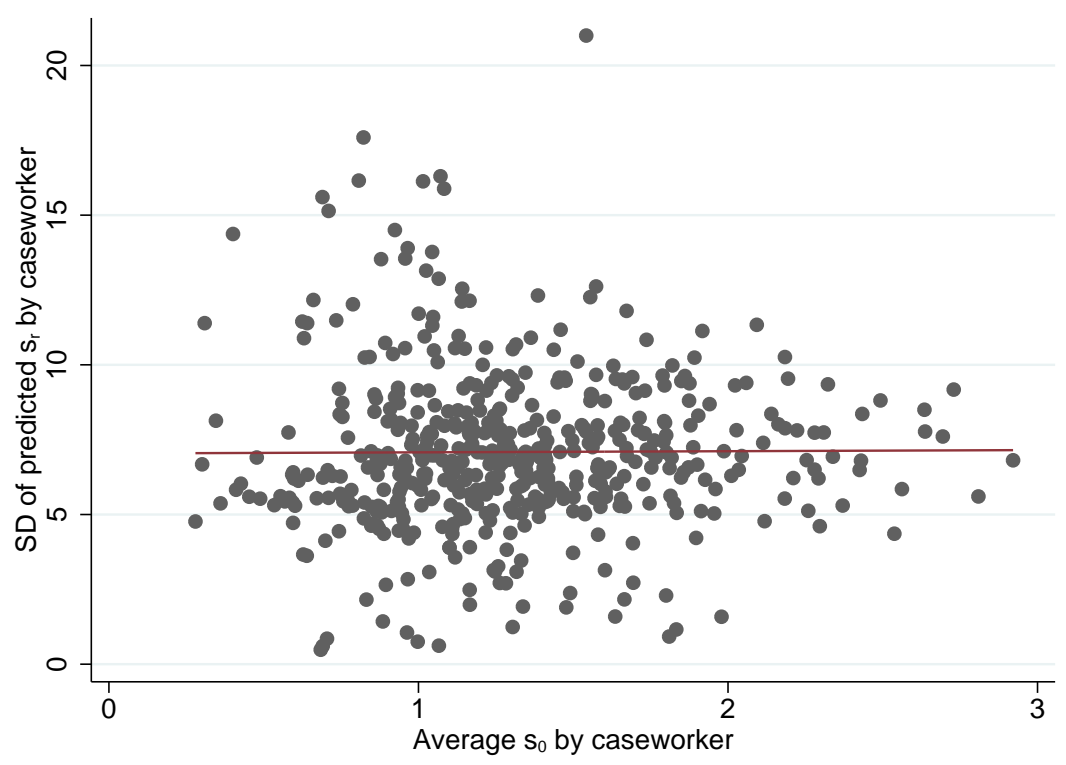


Table 3: Probability of Non-Compliance, Non-Compliance Detection and Occurrence of Benefit Sanction within the first 2 months of UE

\begin{tabular}{lccc}
\hline \hline & $(1)$ & $(2)$ & $(3)$ \\
& Non-Compliance & Detection & Sanction \\
\hline$\Delta_{s_{r}}<-8$ & -0.003 & -0.014 & -0.006 \\
& $(0.014)$ & $(0.011)$ & $(0.008)$ \\
$\Delta_{s_{r}} \epsilon[-8,-7]$ & -0.001 & -0.010 & -0.005 \\
& $(0.011)$ & $(0.009)$ & $(0.006)$ \\
$\Delta_{s_{r}} \epsilon[-6,-5]$ & $0.018^{* *}$ & -0.009 & -0.001 \\
& $(0.008)$ & $(0.007)$ & $(0.005)$ \\
$\Delta_{s_{r}} \epsilon[-4,-3]$ & -0.000 & -0.008 & -0.002 \\
& $(0.006)$ & $(0.005)$ & $(0.004)$ \\
$\Delta_{s_{r}} \epsilon[3,4]$ & $0.014^{* *}$ & $0.010^{*}$ & $0.008^{*}$ \\
& $(0.006)$ & $(0.005)$ & $(0.004)$ \\
$\Delta_{s_{r}} \epsilon[5,6]$ & $0.033^{* * *}$ & $0.019^{* * *}$ & $0.016^{* * *}$ \\
& $(0.008)$ & $(0.007)$ & $(0.005)$ \\
$\Delta_{s_{r}} \epsilon[7,8]$ & $0.042^{* * *}$ & $0.031^{* * *}$ & $0.027^{* * *}$ \\
& $(0.010)$ & $(0.010)$ & $(0.008)$ \\
$\Delta_{s_{r}}>8$ & & & \\
\hline Outcome Mean & $0.040^{* * *}$ & $0.053^{* * *}$ & $0.050^{* * *}$ \\
$\mathrm{~N}$ & $(0.013)$ & $(0.013)$ & $(0.010)$ \\
\hline \hline
\end{tabular}

$* p<0.10, * * p<0.05, * * * p<0.01$. Standard errors are clustered at the caseworker level. The reference category is $\Delta_{s_{r}} \epsilon[-2,2]$. All regressions estimate equation 1 using OLS. They include all identifying fixed effects (discussed in section 5) and all covariates, which control for gender, age, immigration status, civil status, household size, education, employment and unemployment history, quarter and year of UE entry. Summary statistics on all explanatory variables can be found in Appendix A.2. "Non-Compliance" is coded as one if the job seeker submits less than 3/4 of required applications in the first month under the requirement constraint. "Detection" is coded as one if the job seeker receives a warning on non-compliance detection during the first two months of UE. "Sanction" is coded as one if the job seeker receives a benefit sanction for a non-compliance that was detected during the first two months of UE.

Figure 11: Illustration of Results in Table 3, Columns (2) and (3) (with 90\%CIs)

Probability of Detection and Sanction

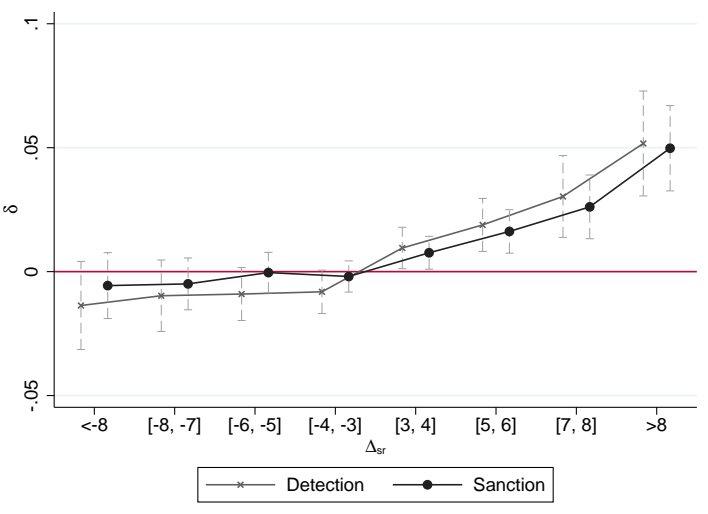


Table 4: Effects on Job Finding Hazard, Censored at Different Durations

\begin{tabular}{|c|c|c|c|c|c|c|c|}
\hline & \multicolumn{3}{|c|}{6 months } & \multicolumn{2}{|c|}{3 months } & \multicolumn{2}{|c|}{24 months } \\
\hline & (1) & (2) & (3) & (4) & $(5)$ & $(6)$ & $(7)$ \\
\hline & Coeff & Coeff & Marg. Effect & Coeff & Marg. Effect & Coeff & Marg. Effect \\
\hline$\Delta_{s_{r}}<-8$ & $\begin{array}{c}-0.017 \\
(0.074)\end{array}$ & $\begin{array}{c}-0.048 \\
(0.072)\end{array}$ & -0.007 & $\begin{array}{c}-0.292^{* * *} \\
(0.094)\end{array}$ & -0.023 & $\begin{array}{c}-0.002 \\
(0.063)\end{array}$ & 0.000 \\
\hline$\Delta_{s_{r}} \epsilon[-8,-7]$ & $\begin{array}{c}0.023 \\
(0.064)\end{array}$ & $\begin{array}{l}-0.007 \\
(0.064)\end{array}$ & -0.001 & $\begin{array}{c}-0.155^{*} \\
(0.082)\end{array}$ & -0.013 & $\begin{array}{l}-0.047 \\
(0.058)\end{array}$ & -0.009 \\
\hline$\Delta_{s_{r}} \epsilon[-6,-5]$ & $\begin{array}{c}-0.032 \\
(0.056)\end{array}$ & $\begin{array}{c}-0.044 \\
(0.057)\end{array}$ & -0.007 & $\begin{array}{l}-0.129 \\
(0.081)\end{array}$ & -0.011 & $\begin{array}{l}-0.019 \\
(0.049)\end{array}$ & -0.004 \\
\hline$\Delta_{s_{r}} \epsilon[-4,-3]$ & $\begin{array}{c}-0.036 \\
(0.038)\end{array}$ & $\begin{array}{l}-0.042 \\
(0.035)\end{array}$ & -0.006 & $\begin{array}{l}-0.079 \\
(0.053)\end{array}$ & -0.007 & $\begin{array}{l}-0.025 \\
(0.029)\end{array}$ & -0.005 \\
\hline$\Delta_{s_{r}} \in[3,4]$ & $\begin{array}{c}0.141^{* * *} \\
(0.038)\end{array}$ & $\begin{array}{c}0.132^{* * *} \\
(0.035)\end{array}$ & 0.021 & $\begin{array}{c}0.175^{* * *} \\
(0.049)\end{array}$ & 0.017 & $\begin{array}{c}0.101^{* * *} \\
(0.029)\end{array}$ & 0.019 \\
\hline$\Delta_{s_{r}} \epsilon[5,6]$ & $\begin{array}{c}0.181^{* * *} \\
(0.056)\end{array}$ & $\begin{array}{c}0.169^{* * *} \\
(0.050)\end{array}$ & 0.027 & $\begin{array}{c}0.300^{* * *} \\
(0.067)\end{array}$ & 0.030 & $\begin{array}{c}0.130 * * * \\
(0.044)\end{array}$ & 0.025 \\
\hline$\Delta_{s_{r}} \epsilon[7,8]$ & $\begin{array}{c}0.259^{* * *} \\
(0.069)\end{array}$ & $\begin{array}{c}0.243^{* * *} \\
(0.061)\end{array}$ & 0.039 & $\begin{array}{c}0.476^{* * *} \\
(0.077)\end{array}$ & 0.050 & $\begin{array}{c}0.172^{* * *} \\
(0.054)\end{array}$ & 0.033 \\
\hline$\Delta_{s_{r}}>8$ & $\begin{array}{c}0.306^{* * * *} \\
(0.095)\end{array}$ & $\begin{array}{c}0.290^{* * *} \\
(0.085)\end{array}$ & 0.048 & $\begin{array}{c}0.507^{* * * *} \\
(0.112)\end{array}$ & 0.054 & $\begin{array}{c}0.198 * * * \\
(0.076)\end{array}$ & 0.039 \\
\hline$X_{i}$ & No & Yes & & Yes & & Yes & \\
\hline Observations & 76404 & 76404 & & 76404 & & 76404 & \\
\hline Exits & 34065 & 34065 & & 14027 & & 54112 & \\
\hline
\end{tabular}

$* p<0.10, * * p<0.05, * * * p<0.01$. Standard errors are clustered at the caseworker level. The reference category is $\Delta_{s_{r}} \epsilon[-2,2]$. Columns (1), (2), (4) and (6) estimate Equation 2 using Maximum Likelihood with durations censored after 180/90/730 days. Columns (3), (5) and (7) report the difference between the survivor function with treatment and the counterfactual survivor function without treatment at the sample average. All columns are based in regressions that include all identifying fixed effects (discussed in section 5). In columns (2) to (7), regressions include all covariates, which control for gender, age, immigration status, civil status, household size, education, employment and unemployment history, quarter and year of UE entry. Summary statistics on all explanatory variables can be found in Appendix A.2.

Figure 13: Illustration of Results in Table 4, (with 90\%CIs)

(a) Effects on Job Finding Hazard

(Columns (2), (4) and (6))

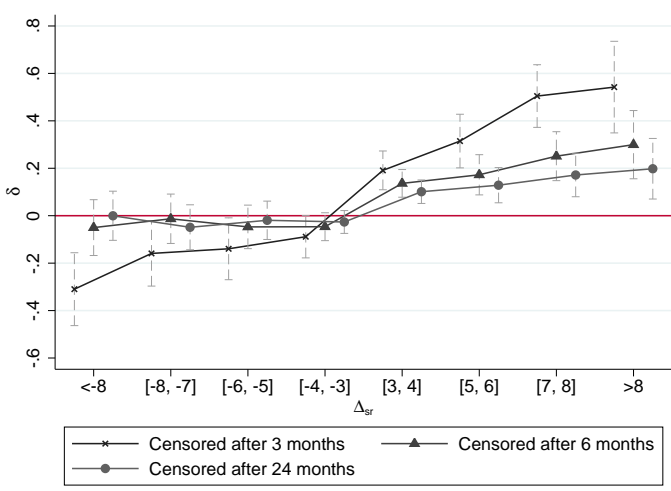

(b) Marginal Effects on Job Finding Probability (Columns (3), (5) and (7))

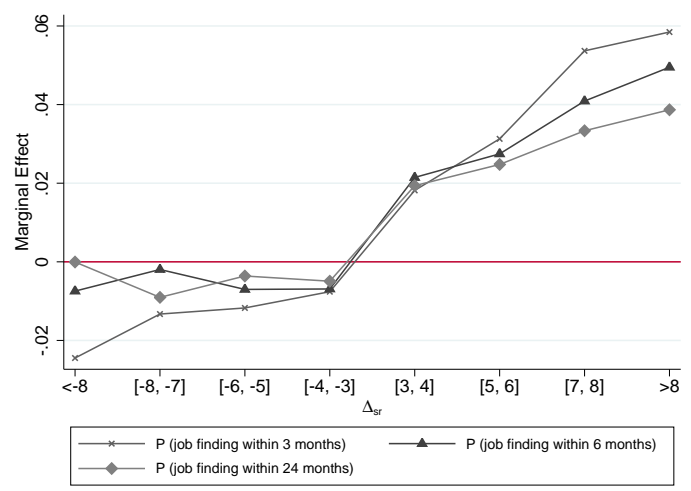


Table 5: Effects on Job Finding Hazard, Subgroup Analysis: Gender and Education

\begin{tabular}{|c|c|c|c|c|c|}
\hline & $\begin{array}{c}(1) \\
\text { Female }\end{array}$ & $\begin{array}{c}(2) \\
\text { Male }\end{array}$ & $\begin{array}{c}(3) \\
\text { Unlearned }\end{array}$ & $\begin{array}{c}(4) \\
\text { Apprenticeship }\end{array}$ & $\begin{array}{c}(5) \\
\text { High School+ }\end{array}$ \\
\hline$\Delta_{s_{r}}<-8$ & $\begin{array}{l}-0.051 \\
(0.111)\end{array}$ & $\begin{array}{c}-0.037 \\
(0.087)\end{array}$ & $\begin{array}{l}-0.053 \\
(0.121)\end{array}$ & $\begin{array}{c}0.015 \\
(0.102)\end{array}$ & $\begin{array}{l}-0.014 \\
(0.164)\end{array}$ \\
\hline$\Delta_{s_{r}} \in[-8,-7]$ & $\begin{array}{c}0.071 \\
(0.107)\end{array}$ & $\begin{array}{l}-0.055 \\
(0.072)\end{array}$ & $\begin{array}{l}-0.036 \\
(0.111)\end{array}$ & $\begin{array}{c}0.071 \\
(0.080)\end{array}$ & $\begin{array}{l}-0.039 \\
(0.126)\end{array}$ \\
\hline$\Delta_{s_{r}} \epsilon[-6,-5]$ & $\begin{array}{c}0.021 \\
(0.079)\end{array}$ & $\begin{array}{l}-0.101 \\
(0.063)\end{array}$ & $\begin{array}{l}-0.023 \\
(0.093)\end{array}$ & $\begin{array}{l}-0.017 \\
(0.069)\end{array}$ & $\begin{array}{l}-0.085 \\
(0.108)\end{array}$ \\
\hline$\Delta_{s_{r}} \in[-4,-3]$ & $\begin{array}{c}0.050 \\
(0.052)\end{array}$ & $\begin{array}{c}-0.095^{* *} \\
(0.041)\end{array}$ & $\begin{array}{l}-0.080 \\
(0.059)\end{array}$ & $\begin{array}{l}-0.028 \\
(0.046)\end{array}$ & $\begin{array}{c}0.081 \\
(0.069)\end{array}$ \\
\hline$\Delta_{s_{r}} \epsilon[3,4]$ & $\begin{array}{c}0.217^{* * *} \\
(0.056)\end{array}$ & $\begin{array}{c}0.073^{* *} \\
(0.035)\end{array}$ & $\begin{array}{c}0.181^{* * *} \\
(0.056)\end{array}$ & $\begin{array}{c}0.106^{* *} \\
(0.041)\end{array}$ & $\begin{array}{c}0.009 \\
(0.073)\end{array}$ \\
\hline$\Delta_{s_{r}} \epsilon[5,6]$ & $\begin{array}{c}0.266^{* * *} \\
(0.079)\end{array}$ & $\begin{array}{c}0.100^{* *} \\
(0.049)\end{array}$ & $\begin{array}{c}0.212^{* *} \\
(0.084)\end{array}$ & $\begin{array}{l}0.106^{*} \\
(0.056)\end{array}$ & $\begin{array}{c}0.116 \\
(0.085)\end{array}$ \\
\hline$\Delta_{s_{r}} \epsilon[7,8]$ & $\begin{array}{c}0.380^{* * *} \\
(0.091)\end{array}$ & $\begin{array}{c}0.142^{* *} \\
(0.061)\end{array}$ & $\begin{array}{c}0.245^{* * *} \\
(0.095)\end{array}$ & $\begin{array}{l}0.162^{* *} \\
(0.069)\end{array}$ & $\begin{array}{l}0.222^{* *} \\
(0.108)\end{array}$ \\
\hline$\Delta_{s_{r}}>8$ & $\begin{array}{c}0.515^{* * *} \\
(0.134)\end{array}$ & $\begin{array}{l}0.135^{*} \\
(0.076)\end{array}$ & $\begin{array}{l}0.325^{* *} \\
(0.140)\end{array}$ & $\begin{array}{l}0.198^{* *} \\
(0.088)\end{array}$ & $\begin{array}{c}0.132 \\
(0.142)\end{array}$ \\
\hline Observations & 30890 & 45514 & 30601 & 32806 & 12997 \\
\hline Exits & 20520 & 13368 & 13004 & 15489 & 5395 \\
\hline
\end{tabular}

$p<\overline{\overline{0.10, * * p<0.05, * * * p<0.01 \text {. Standard errors are clustered at the caseworker level. The reference category }}}$ is $\Delta_{s_{r}} \epsilon[-2,2]$. Regressions estimate equation 2 using Maximum Likelihood, with durations censored after 180 days of unemployment. They include all identifying fixed effects (discussed in section 5) and all covariates, which control for gender, age, immigration status, civil status, education, employment and unemployment history, quarter and year of UE entry. Summary statistics on all explanatory variables can be found in Appendix A.2. "Unlearned" job seekers have neither an educational nor a practical formal degree. Job seekers with an apprenticeship followed a practical education. Job seeker with "High School+" have at least the highest Swiss high school degree ("Abitur").

Figure 14: Illustration of Results in Table 5 (with 90\%CIs)
(a) Gender
(b) Education
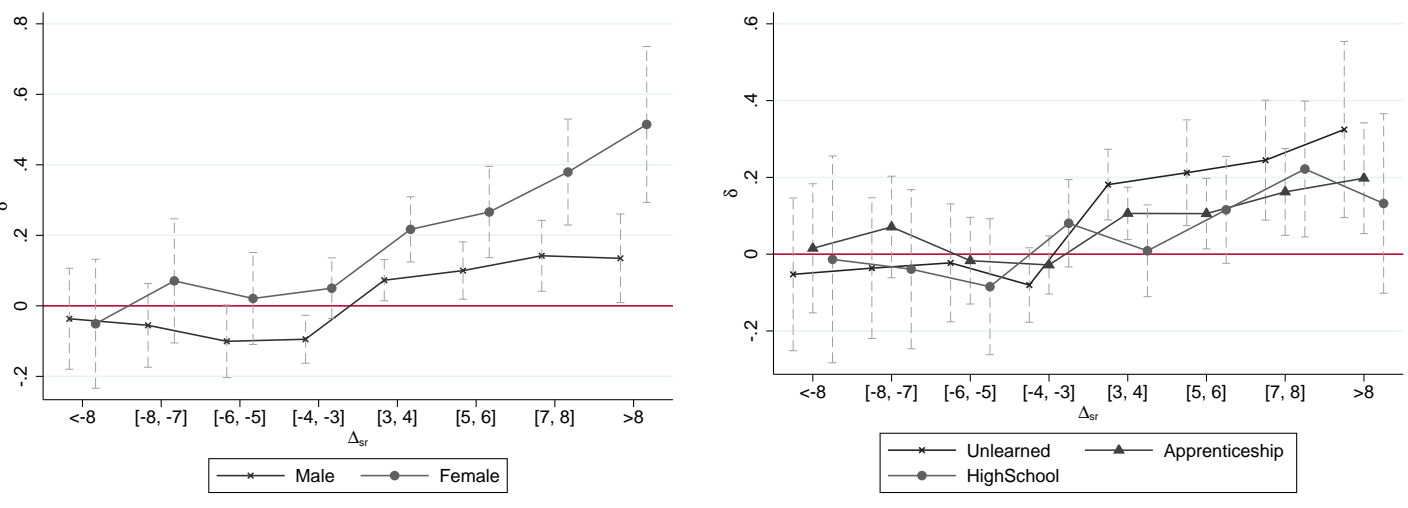
Table 6: Effects on Job Finding Hazard, Subgroup Analysis: Occupation and Function in Last Job

\begin{tabular}{lccccc}
\hline \hline & $(1)$ & $(2)$ & $(3)$ & $(4)$ & $(5)$ \\
& Blue Collar & Service Low & Service High & Support Function & Professional+ Function \\
\hline$\Delta_{s_{r}}<-8$ & 0.016 & -0.000 & 0.018 & -0.066 & 0.031 \\
& $(0.123)$ & $(0.130)$ & $(0.100)$ & $(0.112)$ & $(0.080)$ \\
$\Delta_{s_{r}} \epsilon[-8,-7]$ & 0.094 & -0.027 & 0.062 & -0.043 & 0.067 \\
& $(0.101)$ & $(0.132)$ & $(0.080)$ & $(0.112)$ & $(0.065)$ \\
$\Delta_{s_{r}} \epsilon[-6,-5]$ & -0.023 & -0.049 & 0.023 & -0.106 & 0.025 \\
& $(0.066)$ & $(0.097)$ & $(0.072)$ & $(0.085)$ & $(0.053)$ \\
$\Delta_{s_{r}} \epsilon[-4,-3]$ & -0.019 & -0.078 & 0.048 & $-0.096^{*}$ & 0.004 \\
& $(0.053)$ & $(0.074)$ & $(0.046)$ & $(0.055)$ & $(0.034)$ \\
$\Delta_{s_{r}} \epsilon[3,4]$ & -0.026 & $0.250^{* * *}$ & $0.114^{* *}$ & $0.197^{* * *}$ & $0.068^{*}$ \\
$\Delta_{s_{r}} \epsilon[5,6]$ & $(0.045)$ & $(0.061)$ & $(0.045)$ & $(0.048)$ & $(0.035)$ \\
$\Delta_{s_{r}} \epsilon[7,8]$ & -0.014 & $0.268^{* * *}$ & $0.121^{* *}$ & $0.244^{* * *}$ & $0.076^{*}$ \\
$\Delta_{s_{r}}>8$ & $(0.060)$ & $(0.090)$ & $(0.056)$ & $(0.074)$ & $(0.046)$ \\
\hline Observations & -0.050 & $0.431^{* * *}$ & $0.205^{* * *}$ & $0.362^{* * *}$ & $0.113^{* *}$ \\
Exits & $(0.078)$ & $(0.096)$ & $(0.069)$ & $(0.084)$ & $(0.054)$ \\
\hline \hline
\end{tabular}

$* p<0.10, * * p<0.05, * * * p<0.01$. Standard errors are clustered at the caseworker level. The reference category is $\Delta_{s_{r}} \epsilon[-2,2]$. Regressions estimate equation 2 using Maximum Likelihood, with durations censored after 180 days of unemployment. They include all identifying fixed effects (discussed in section 5) and all covariates, which control for gender, age, immigration status, civil status, education, employment and unemployment history, quarter and year of UE entry. Summary statistics on all explanatory variables can be found in Appendix A.2.

Figure 15: Illustration of Results in Table 6 (with 90\%CIs)

(a) Occupation

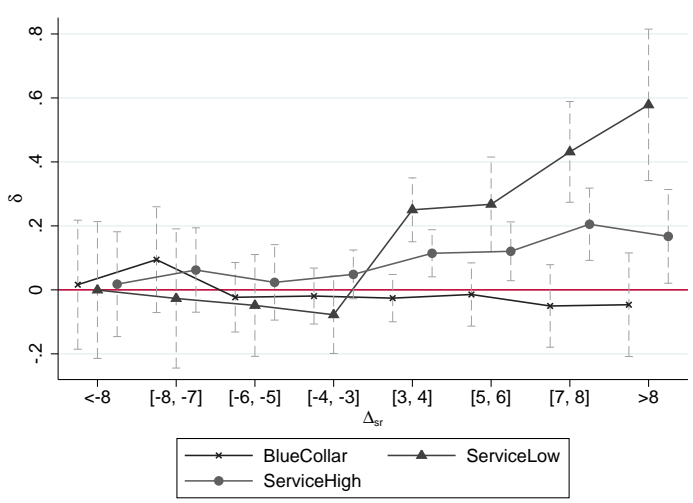

(b) Function in Last Job

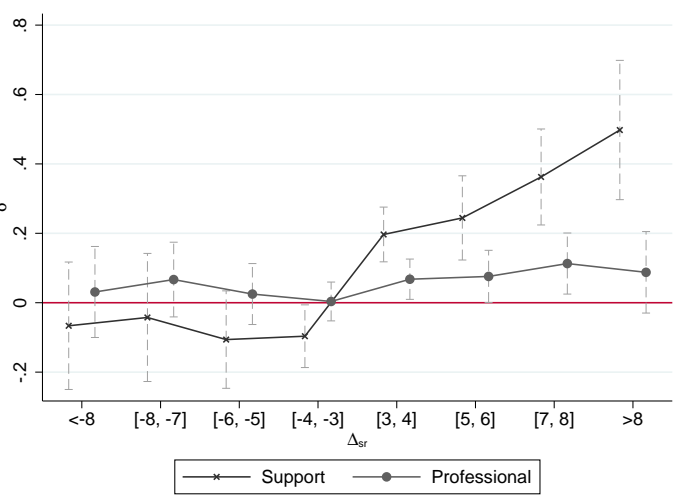


Table 7: Effects on Job Finding Hazard, Subgroup Analysis: Vacancy Rate

\begin{tabular}{lccc}
\hline \hline & $(1)$ & $(2)$ & $(3)$ \\
& Low Vacancy Rate & Medium Vacancy Rate & High Vacancy Rate \\
\hline$\Delta_{s_{r}}<-8$ & -0.012 & -0.213 & -0.075 \\
& $(0.134)$ & $(0.138)$ & $(0.111)$ \\
$\Delta_{s_{r}} \epsilon[-8,-7]$ & -0.005 & -0.066 & -0.029 \\
& $(0.110)$ & $(0.118)$ & $(0.087)$ \\
$\Delta_{s_{r}} \epsilon[-6,-5]$ & -0.067 & $-0.181^{*}$ & 0.004 \\
& $(0.077)$ & $(0.103)$ & $(0.083)$ \\
$\Delta_{s_{r}} \epsilon[-4,-3]$ & -0.063 & -0.096 & -0.027 \\
& $(0.058)$ & $(0.067)$ & $(0.053)$ \\
$\Delta_{s_{r}} \epsilon[3,4]$ & $0.111^{* *}$ & $0.139^{* *}$ & $0.133^{* * *}$ \\
$\Delta_{s_{r}} \epsilon[5,6]$ & $(0.054)$ & $(0.058)$ & $(0.048)$ \\
$\Delta_{s_{r}} \epsilon[7,8]$ & 0.080 & $0.166^{* *}$ & $0.237^{* * *}$ \\
$\Delta_{s_{r}}>8$ & $(0.067)$ & $(0.076)$ & $(0.072)$ \\
\hline Observations & $0.147^{*}$ & $0.254^{* *}$ & $0.317^{* * *}$ \\
Exits & $(0.081)$ & $(0.100)$ & $(0.085)$ \\
\hline \hline
\end{tabular}

$* p<\overline{\overline{0.10, * * p<0.05, * * * p<0.01 \text {. Standard errors are clustered at the caseworker level. The reference category }}}$ is $\Delta_{s_{r}} \epsilon[-2,2]$. Regressions estimate equation 2 using Maximum Likelihood, with durations censored after 180 days of unemployment. They include all identifying fixed effects (discussed in section 5) and all covariates, which control for gender, age, immigration status, civil status, education, employment and unemployment history, quarter and year of UE entry. Summary statistics on all explanatory variables can be found in Appendix A.2. Vacancy rates are calculated as the ration of posted vacancies over job seekers on a month-region basis. They are assigned to the job seeker depending on his month of registration at the PES. "Low", "medium" and "high" vacancy rates are understood in relative terms, i.e. we divide the distribution of vacancy rates by 3 to assign job seekers one of these categories. The mean vacancy rate in our sample is .086.

Figure 16: Illustration of Results in Table 7 (with 90\%CIs)

Relative Vacancy Rate

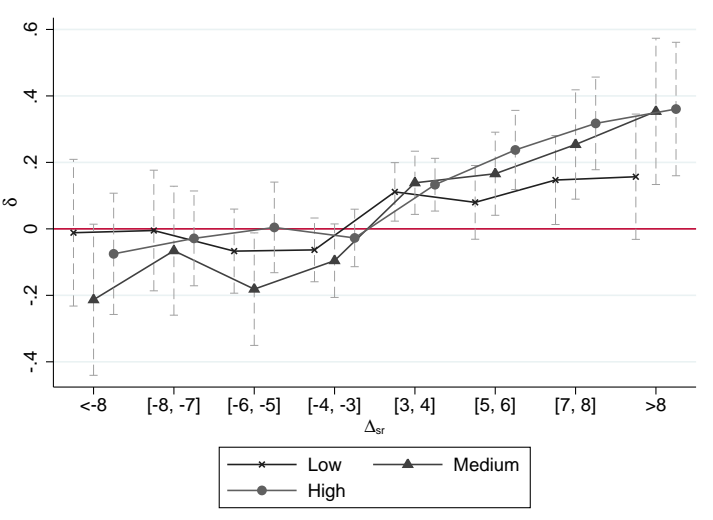


Table 8: Probability of Recurrence to Unemployment within 6/12 Months after Job Finding

\begin{tabular}{|c|c|c|c|c|}
\hline & $\begin{array}{c}(1) \\
6 \text { Months, All }\end{array}$ & $\begin{array}{c}(2) \\
6 \text { Months, Unlearned }\end{array}$ & $\begin{array}{c}(3) \\
12 \text { Months, All }\end{array}$ & $\begin{array}{c}(4) \\
12 \text { Months, Unlearned }\end{array}$ \\
\hline$\Delta_{s_{r}}<-8$ & $\begin{array}{c}-0.050^{* * *} \\
(0.019)\end{array}$ & $\begin{array}{c}-0.081^{* * *} \\
(0.029)\end{array}$ & $\begin{array}{l}-0.000 \\
(0.021)\end{array}$ & $\begin{array}{c}0.002 \\
(0.029)\end{array}$ \\
\hline$\Delta_{s_{r}} \epsilon[-8,-7]$ & $\begin{array}{c}-0.042^{* * *} \\
(0.016)\end{array}$ & $\begin{array}{c}-0.079^{* * *} \\
(0.025)\end{array}$ & $\begin{array}{c}-0.021 \\
(0.016)\end{array}$ & $\begin{array}{c}-0.034 \\
(0.023)\end{array}$ \\
\hline$\Delta_{s_{r}} \in[-6,-5]$ & $\begin{array}{c}-0.033^{* * *} \\
(0.012)\end{array}$ & $\begin{array}{c}-0.067^{* * *} \\
(0.021)\end{array}$ & $\begin{array}{l}-0.002 \\
(0.013)\end{array}$ & $\begin{array}{c}-0.033^{*} \\
(0.019)\end{array}$ \\
\hline$\Delta_{s_{r}} \in[-4,-3]$ & $\begin{array}{c}-0.021^{* *} \\
(0.009)\end{array}$ & $\begin{array}{c}-0.031^{* *} \\
(0.014)\end{array}$ & $\begin{array}{c}0.001 \\
(0.009)\end{array}$ & $\begin{array}{l}-0.000 \\
(0.015)\end{array}$ \\
\hline$\Delta_{s_{r}} \in[3,4]$ & $\begin{array}{c}0.021^{* * *} \\
(0.008)\end{array}$ & $\begin{array}{c}0.039^{* * *} \\
(0.012)\end{array}$ & $\begin{array}{c}0.006 \\
(0.008)\end{array}$ & $\begin{array}{c}0.005 \\
(0.013)\end{array}$ \\
\hline$\Delta_{s_{r}} \epsilon[5,6]$ & $\begin{array}{l}0.023^{* *} \\
(0.011)\end{array}$ & $\begin{array}{c}0.054^{* * *} \\
(0.017)\end{array}$ & $\begin{array}{l}-0.004 \\
(0.010)\end{array}$ & $\begin{array}{l}-0.000 \\
(0.016)\end{array}$ \\
\hline$\Delta_{s_{r}} \epsilon[7,8]$ & $\begin{array}{c}0.047^{* * *} \\
(0.015)\end{array}$ & $\begin{array}{c}0.091^{* * *} \\
(0.021)\end{array}$ & $\begin{array}{c}0.004 \\
(0.014)\end{array}$ & $\begin{array}{c}0.012 \\
(0.021)\end{array}$ \\
\hline$\Delta_{s_{r}}>8$ & $\begin{array}{c}0.063^{* * *} \\
(0.020)\end{array}$ & $\begin{array}{c}0.112^{* * *} \\
(0.028)\end{array}$ & $\begin{array}{c}0.001 \\
(0.018)\end{array}$ & $\begin{array}{c}0.007 \\
(0.028)\end{array}$ \\
\hline $\begin{array}{l}\text { Outcome Mean } \\
\mathrm{N}\end{array}$ & $\begin{array}{l}0.138 \\
76404\end{array}$ & $\begin{array}{l}0.167 \\
30601\end{array}$ & $\begin{array}{l}0.267 \\
76404\end{array}$ & $\begin{array}{l}0.341 \\
30601\end{array}$ \\
\hline
\end{tabular}

$* p<0.10, * * p<0.05, * * * p<0.01$. Standard errors are clustered at the caseworker level. The reference category is $\Delta_{s} \epsilon[-2,2]$. All regressions estimate Equation 1 using OLS and include all identifying fixed effects (discussed in section 5) and all covariates, which control for gender, age, immigration status, civil status, education, employment and unemployment history, quarter and year of UE entry. Summary statistics on all explanatory variables can be found in Appendix A.2. In addition, the incidence of benefit sanctions and the duration of unemployment in the first spell are controlled for. The outcome is coded as 1 if the job seeker exits employment and recurs to unemployment after within the following (6/12) months. "Unlearned" job seekers have neither an educational nor a practical formal degree.

Figure 17: Illustration of Results in Table 8, Column (1) (with 90\%CIs)

Probability of Recurrence to UE within 6 Months

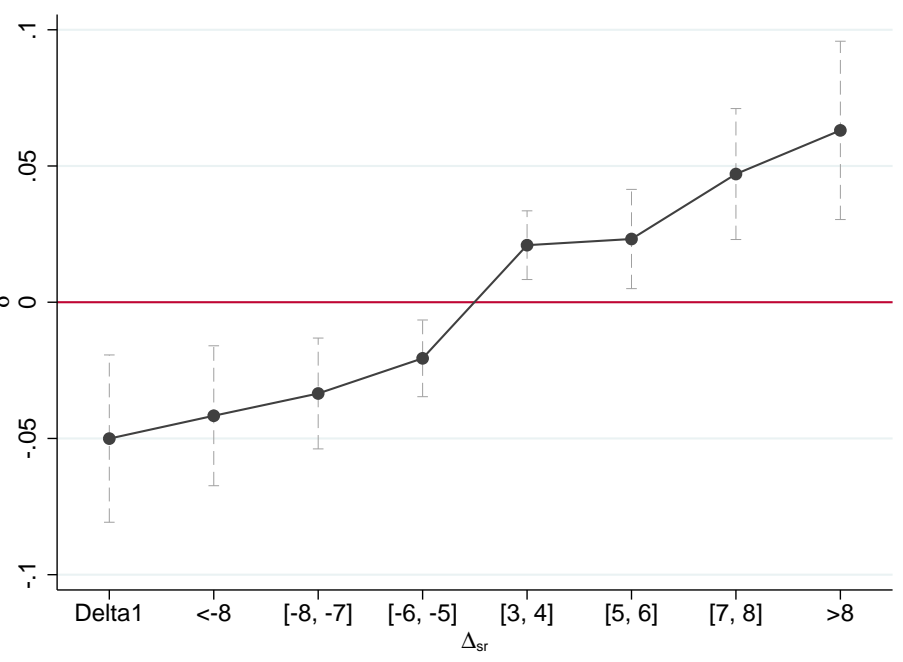


Table 9: Decomposition of Effect on Probability of Job Finding within 6 Month: Stable (no recurrence) vs. Unstable Jobs (recurrence within 6 Months)

\begin{tabular}{|c|c|c|c|}
\hline & $\begin{array}{c}(1) \\
\text { Job Finding }\end{array}$ & $\begin{array}{c}\text { Job Finding and Recurrence } \\
\text { Job }\end{array}$ & $\begin{array}{c} \\
\text { Job Finding and No Recurrence }\end{array}$ \\
\hline$\Delta_{s_{r}}<-8$ & $\begin{array}{c}0.025 \\
(0.023)\end{array}$ & $\begin{array}{c}-0.036^{* *} \\
(0.018)\end{array}$ & $\begin{array}{l}0.062^{* *} \\
(0.029)\end{array}$ \\
\hline$\Delta_{s_{r}} \epsilon[-8,-7]$ & $\begin{array}{c}0.026 \\
(0.017)\end{array}$ & $\begin{array}{c}-0.033^{* *} \\
(0.016)\end{array}$ & $\begin{array}{c}0.059^{* * *} \\
(0.022)\end{array}$ \\
\hline$\Delta_{s_{r}} \epsilon[-6,-5]$ & $\begin{array}{c}0.013 \\
(0.013)\end{array}$ & $\begin{array}{c}-0.030^{* *} \\
(0.012)\end{array}$ & $\begin{array}{c}0.043^{* * *} \\
(0.016)\end{array}$ \\
\hline$\Delta_{s_{r}} \epsilon[-4,-3]$ & $\begin{array}{c}0.002 \\
(0.009)\end{array}$ & $\begin{array}{c}-0.019^{* *} \\
(0.009)\end{array}$ & $\begin{array}{l}0.021^{*} \\
(0.012)\end{array}$ \\
\hline$\Delta_{s_{r}} \epsilon[3,4]$ & $\begin{array}{c}0.023^{* * *} \\
(0.008)\end{array}$ & $\begin{array}{c}0.025^{* * *} \\
(0.008)\end{array}$ & $\begin{array}{l}-0.003 \\
(0.011)\end{array}$ \\
\hline$\Delta_{s_{r}} \epsilon[5,6]$ & $\begin{array}{c}0.032^{* * *} \\
(0.011)\end{array}$ & $\begin{array}{c}0.042^{* * *} \\
(0.012)\end{array}$ & $\begin{array}{l}-0.010 \\
(0.015)\end{array}$ \\
\hline$\Delta_{s_{r}} \epsilon[7,8]$ & $\begin{array}{l}0.033^{* *} \\
(0.015)\end{array}$ & $\begin{array}{c}0.059^{* * *} \\
(0.016)\end{array}$ & $\begin{array}{l}-0.026 \\
(0.021)\end{array}$ \\
\hline$\Delta_{s_{r}}>8$ & $\begin{array}{l}0.045^{* *} \\
(0.019)\end{array}$ & $\begin{array}{c}0.085^{* * *} \\
(0.023)\end{array}$ & $\begin{array}{l}-0.040 \\
(0.028)\end{array}$ \\
\hline $\begin{array}{l}\text { Outcome Mean } \\
\mathrm{N}\end{array}$ & $\begin{array}{l}0.379 \\
76404\end{array}$ & $\begin{array}{l}0.073 \\
76404\end{array}$ & $\begin{array}{l}0.305 \\
76404\end{array}$ \\
\hline
\end{tabular}

$* p<0.10, * * p<0.05, * * * p<0.01$. Standard errors are clustered at the caseworker level. The reference category is $\Delta_{s_{r}} \epsilon[-2,2]$. All regressions estimate Equation 1 using OLS and include all identifying fixed effects (discussed in section 5) and all covariates, which control for gender, age, immigration status, civil status, education, employment and unemployment history, quarter and year of UE entry. Summary statistics on all explanatory variables can be found in Appendix A.2. In addition, the incidence of benefit sanctions and the duration of unemployment in the first spell are controlled for. 
Table 10: Robustness Check: additional controls
(1)
(2)
(3)
(4)

Baseline Results $\quad \mathrm{s} 0 *$ Education $\quad \mathrm{s} 0 *$ Gender Detection and Sanction

\begin{tabular}{|c|c|c|c|c|}
\hline$\Delta_{s_{r}}<-8$ & $\begin{array}{l}-0.048 \\
(0.072)\end{array}$ & $\begin{array}{l}-0.045 \\
(0.073)\end{array}$ & $\begin{array}{l}-0.051 \\
(0.072)\end{array}$ & $\begin{array}{l}-0.042 \\
(0.071)\end{array}$ \\
\hline$\Delta_{s_{r}} \in[-8,-7]$ & $\begin{array}{l}-0.007 \\
(0.064)\end{array}$ & $\begin{array}{l}-0.012 \\
(0.063)\end{array}$ & $\begin{array}{l}-0.010 \\
(0.064)\end{array}$ & $\begin{array}{l}-0.001 \\
(0.063)\end{array}$ \\
\hline$\Delta_{s_{r}} \epsilon[-6,-5]$ & $\begin{array}{l}-0.044 \\
(0.057)\end{array}$ & $\begin{array}{l}-0.043 \\
(0.058)\end{array}$ & $\begin{array}{l}-0.046 \\
(0.057)\end{array}$ & $\begin{array}{l}-0.040 \\
(0.056)\end{array}$ \\
\hline$\Delta_{s_{r}} \epsilon[-4,-3]$ & $\begin{array}{l}-0.042 \\
(0.035)\end{array}$ & $\begin{array}{l}-0.037 \\
(0.036)\end{array}$ & $\begin{array}{l}-0.043 \\
(0.035)\end{array}$ & $\begin{array}{l}-0.039 \\
(0.035)\end{array}$ \\
\hline$\Delta_{s_{r}} \epsilon[3,4]$ & $\begin{array}{c}0.132^{* * *} \\
(0.035)\end{array}$ & $\begin{array}{c}0.136^{* * *} \\
(0.035)\end{array}$ & $\begin{array}{c}0.133^{* * *} \\
(0.035)\end{array}$ & $\begin{array}{c}0.127^{* * *} \\
(0.034)\end{array}$ \\
\hline$\Delta_{s_{r}} \epsilon[5,6]$ & $\begin{array}{c}0.169^{* * *} \\
(0.050)\end{array}$ & $\begin{array}{c}0.173^{* * *} \\
(0.051)\end{array}$ & $\begin{array}{c}0.170^{* * *} \\
(0.051)\end{array}$ & $\begin{array}{c}0.160^{* * *} \\
(0.050)\end{array}$ \\
\hline$\Delta_{s_{r}} \epsilon[7,8]$ & $\begin{array}{c}0.243^{* * *} \\
(0.061)\end{array}$ & $\begin{array}{c}0.248^{* * *} \\
(0.062)\end{array}$ & $\begin{array}{c}0.243^{* * *} \\
(0.061)\end{array}$ & $\begin{array}{c}0.230^{* * *} \\
(0.060)\end{array}$ \\
\hline$\Delta_{s_{r}}>8$ & $\begin{array}{c}0.290^{* * *} \\
(0.085)\end{array}$ & $\begin{array}{c}0.297^{* * *} \\
(0.087)\end{array}$ & $\begin{array}{c}0.291^{* * *} \\
(0.085)\end{array}$ & $\begin{array}{c}0.276^{* * *} \\
(0.084)\end{array}$ \\
\hline Observations & 76404 & 76404 & 76404 & 76404 \\
\hline Exits & 33888 & 33888 & 33888 & 33888 \\
\hline
\end{tabular}

$* p<0.10, * * p<0.05, * * * p<0.01$. Standard errors are clustered at the caseworker level. The reference category is $\Delta_{s_{r}} \epsilon[-2,2]$. All regressions estimate Equation 2 using Maximum Likelihood, with durations censored after 180 days of unemployment. They include all identifying fixed effects (discussed in section 5) and all covariates, which control for gender, age, immigration status, civil status, education, employment and unemployment history, quarter and year of UE entry. Summary statistics on all explanatory variables can be found in Appendix A.2. In Column (2), $\gamma^{s_{0}}$ is interacted with indicators for no education, apprenticeship and high education. In Column (3), $\gamma^{s_{0}}$ is interacted with a gender dummy. In Column (4), the detection and the enforcement of a beneft sanction are introduced as events that are allowed to shift the job finding hazard. 
Table 11: Robustness Check: Subsample Analysis

\begin{tabular}{|c|c|c|c|c|}
\hline & $\begin{array}{c}(1) \\
\text { Baseline Results }\end{array}$ & $\begin{array}{c}(2) \\
\text { Not Imputed }\end{array}$ & $\begin{array}{c}(3) \\
\text { Before Registration }\end{array}$ & $\begin{array}{c}(4) \\
\text { First UE }\end{array}$ \\
\hline$\Delta_{s_{r}}<-8$ & $\begin{array}{l}-0.048 \\
(0.072)\end{array}$ & $\begin{array}{l}-0.098 \\
(0.076)\end{array}$ & $\begin{array}{c}0.031 \\
(0.107)\end{array}$ & $\begin{array}{l}-0.057 \\
(0.095)\end{array}$ \\
\hline$\Delta_{s_{r}} \epsilon[-8,-7]$ & $\begin{array}{l}-0.007 \\
(0.064)\end{array}$ & $\begin{array}{l}-0.053 \\
(0.066)\end{array}$ & $\begin{array}{c}0.015 \\
(0.082)\end{array}$ & $\begin{array}{c}0.033 \\
(0.080)\end{array}$ \\
\hline$\Delta_{s_{r}} \epsilon[-6,-5]$ & $\begin{array}{l}-0.044 \\
(0.057)\end{array}$ & $\begin{array}{l}-0.090 \\
(0.060)\end{array}$ & $\begin{array}{l}-0.086 \\
(0.084)\end{array}$ & $\begin{array}{l}-0.050 \\
(0.066)\end{array}$ \\
\hline$\Delta_{s_{r}} \epsilon[-4,-3]$ & $\begin{array}{l}-0.042 \\
(0.035)\end{array}$ & $\begin{array}{c}-0.086^{* *} \\
(0.038)\end{array}$ & $\begin{array}{l}-0.057 \\
(0.047)\end{array}$ & $\begin{array}{l}-0.021 \\
(0.045)\end{array}$ \\
\hline$\Delta_{s_{r}} \epsilon[3,4]$ & $\begin{array}{c}0.133^{* * *} \\
(0.035)\end{array}$ & $\begin{array}{c}0.158^{* * *} \\
(0.037)\end{array}$ & $\begin{array}{c}0.074 \\
(0.048)\end{array}$ & $\begin{array}{c}0.137^{* * *} \\
(0.042)\end{array}$ \\
\hline$\Delta_{s_{r}} \epsilon[5,6]$ & $\begin{array}{c}0.169^{* * *} \\
(0.050)\end{array}$ & $\begin{array}{c}0.198^{* * *} \\
(0.054)\end{array}$ & $\begin{array}{l}0.149^{* *} \\
(0.065)\end{array}$ & $\begin{array}{c}0.176^{* * *} \\
(0.057)\end{array}$ \\
\hline$\Delta_{s_{r}} \epsilon[7,8]$ & $\begin{array}{c}0.243^{* * *} \\
(0.061)\end{array}$ & $\begin{array}{c}0.276^{* * *} \\
(0.065)\end{array}$ & $\begin{array}{c}0.229^{* * *} \\
(0.077)\end{array}$ & $\begin{array}{c}0.259^{* * *} \\
(0.069)\end{array}$ \\
\hline$\Delta_{s_{r}}>8$ & $\begin{array}{c}0.290^{* * *} \\
(0.085)\end{array}$ & $\begin{array}{c}0.364^{* * *} \\
(0.088)\end{array}$ & $\begin{array}{l}0.238^{* *} \\
(0.112)\end{array}$ & $\begin{array}{c}0.282^{* * *} \\
(0.093)\end{array}$ \\
\hline Observations & 76404 & 70106 & 32637 & 59989 \\
\hline Exits & 33888 & 29798 & 15790 & 24748 \\
\hline
\end{tabular}

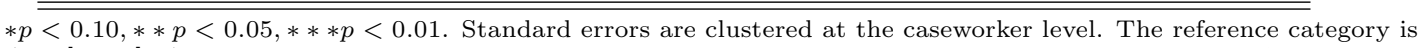
$\Delta_{s_{r}} \epsilon[-2,2]$. All regressions estimate Equation 2 using Maximum Likelihood, with durations censored after 180 days of unemployment. They include all identifying fixed effects (discussed in section 5) and all covariates, which control for gender, age, immigration status, civil status, education, employment and unemployment history, quarter and year of UE entry. Summary statistics on all explanatory variables can be found in Appendix A.2. 


\section{References}

Abbring, J. H., G. J. van den Berg, And J. C. van Ours (2005): "The Effect of Unemployment Insurance Sanctions on the Transition Rate from Unemployment to Employment," The Economic Journal, $115,602-630$.

Arni, P., R. Lalive, And J. C. Van Ours (2013): "How Effective Are Unemployment Benefit Sanctions? Looking Beyond Unemployment Exit," Journal of Applied Econometrics, 28, 1153-1178.

Ashenfelter, O., D. Ashmore, and O. Deschenes (2005): "Do unemployment insurance recipients actively seek work? Evidence from randomized trials in four U.S. States," Journal of Econometrics, $125,53-75$.

Caliendo, M., K. Tatsiramos, and A. Uhlendorff (2013): "Benefit Duration, Unemployment Duration And Job Match Quality: A Regression-Discontinuity Approach," Journal of Applied Econometrics, $28,604-627$.

Card, D., J. Kluve, And A. Weber (2010): "Active Labour Market Policy Evaluations: A MetaAnalysis," Economic Journal, 120.

CARD, D. AND P. B. Levine (2000): "Extended benefits and the duration of UI spells: evidence from the New Jersey extended benefit program," Journal of Public Economics, 78, 107-138.

Card, D., A. Mas, E. Moretti, And E. Saez (2012): "Inequality at Work: The Effect of Peer Salaries on Job Satisfaction," American Economic Review, 102(6), 2981-3003.

Chetty, R. (2008): "Moral Hazard versus Liquidity and Optimal Unemployment Insurance," Journal of Political Economy, 116, 173-234.

Dahl, G. B., A. R. Kostol, And M. Mogstad (forthcoming): "Family Welfare Cultures," Quarterly Journal of Economics.

Della Vigna, S. And D. Paserman (2005): "Job Search and Impatience," Journal of Labor Economics, $23,527-588$.

DellaVigna, S., A. Lindner, B. Reizer, and J. F. Schmieder (2014): "Reference-Dependent Job Search: Evidence from Hungary," mimeo.

Falk, A., D. Huffman, and U. Sunde (2006): "Self Confidence and Search," IZA DP 2525.

Fehr, E. And L. Goette (2007): "Do Workers Work More if Wages Are High? Evidence from a Randomized Field Experiment," American Economic Review, 97, 298-317.

French, E. And J. Song (2006): "The Effect of Disability Insurance Receipt on Labor Supply," American Economic Journal: Economic Policy, vol. 6(2), 291-337.

Hopenhayn, H. And J. P. Nicolini (1997): "Optimal Unemployment Insurance," Journal of Political Economy, 105, 412-38.

Hullegie, P. And J. VAn Ours (2005): "Seek and ye shall find: how search requirements affect job finding rates of older workers," De Economist, 162.

Hunt, J. (1995): "The Effect of Unemployment Compensation on Unemployment Duration in Germany," Journal of Labor Economics, 13, 88-120.

Johnson, T. And D. Klepinger (1994): "Experimental evidence on Unemployment Insurance worksearch policies," Journal of Human Resources, 29,3, 695-717. 
Kahneman, D., J. L. Knetsch, and R. Thaler (1986): "Fairness as a Constraint on Profit Seeking: Entitlements in the Market," American Economic Review, 4, 728-41.

Katz, L. F. AND B. D. Meyer (1990): "The impact of the potential duration of unemployment benefits on the duration of unemployment," Journal of Public Economics, 41, 45-72.

Klepinger, D., T. Johnson, And J. Joesch (2002): "Effects of Unemployment Insurance work-search requirements: The Maryland Experiment," Industrial and Labor Relations Review, 56,1, 3-22.

KLInG, J. (2006): "Incarceration Length, Employment, and Earnings," American Economic Review, vol. $96(3), 863-876$.

Lalive, R., J. C. van Ours, and J. Zweimueller (2005): "The Effect of Benefit Sanctions on the Duration of Unemployment," Journal of the European Economic Association, 3, 1386-1417.

MAnning, A. (2009): "You can't always get what you want: The impact of the UK Jobseeker's Allowance," Labour Economics, 16, 239-250.

MCVICAR, D. (2008): "Job search monitoring intensity, unemployment exit and job entry: Quasiexperimental evidence from the UK," Labour Economics, 15, 1451-1468.

Meyer, B. D. (1990): “Unemployment Insurance and Unemployment Spells," Econometrica, 58, 757-82. (1995): "Lessons from the US unemployment insurance experiments," Journal of Economic Literature, 33, 91-131.

Mortensen, D. T. (1987): "Job search and labor market analysis," Handbook of labor economics, Elsevier.

Pavoni, N. And G. Violante (2007): "Optimal Welfare-to-Work Programs," Review of Economic Studies, 1, 283-318.

Petrongolo, B. (2009): "The long-term effects of job search requirements: Evidence from the UK JSA reform," Journal of Public Economics, 93, 1234-1253.

Schmieder, J. F., T. V. Wachter, And S. Bender (2012): "The Effects of Extended Unemployment Insurance Over the Business Cycle: Evidence from Regression Discontinuity Estimates Over 20 Years," The Quarterly Journal of Economics, 127, 701-752.

Spinnewijn, J. (forthcoming): "Unemployed but Optimistic: Optimal Insurance Design with Biased Beliefs," Journal of the European Economic Association.

Van den Berg, G. J., V. Der KlaAuw, and J. C. Van Ours (2004): "Punitive Sanctions and the Transition Rate from Welfare to Work," Journal of Labor Economics, 22, 211-241.

Van den Berg, G. J. And B. Van der KlaAuw (2006): "Counseling And Monitoring Of Unemployed Workers: Theory And Evidence From A Controlled Social Experiment," International Economic Review, 47, 895-936.

Van der KlaAuw, B. And J. C. Van Ours (2013): "Carrot and Stick: How Re-Employment Bonuses and Benefit Sanctions Affect Exit Rates from Welfare," Journal of Applied Econometrics, 28, 275-296.

Venn, D. (2012): "Eligibility Criteria for Unemployment Benefits: Quantitative Indicators for OECD and EU Countries," OECD Social, Employment and Migration Working Paper 131, OECD Publishing. 


\section{A Appendix}

\section{A.1 Data Appendix}

\section{A.1.1 Sampling criteria for job search data}

The database on search monitoring contains one entry for each calender month during which the job seeker had a legal obligation to search. There are several reasons for which job seekers may be unaffected or only partly affected by this obligation during their spell. We want to exclude these job seekers, as our analysis focuses on requirement effects for individuals who are fully subject to the search obligation. To this purpose, we make the following sampling restrictions and plausability assumptions:

First, job seekers are by definition unaffected by the search obligation if they exit unemployment within one month of unemployment or before their first caseworker meeting takes place (in sum $8.9 \%){ }^{40}$ We also exclude job seekers for whom no first caseworker meeting is reported during the first 90 days of unemployment $(1.8 \%)$, as these are most likely special cases. In addition, we exclude job seekers whose previous unemployment spell ended less than a month previous to their current registration $(1.2 \%)$. These are again most likely particular cases to which the institutional setting underlying our analysis does not apply.

For the remaining sample, there is still the possibility that job seekers are systematically exempted from the monitoring regime because they qualify for special exemption reasons (maternity, preparation of self-employment, participation at a long-run training program etc.) or because they exited unemployment before the monitoring regime became effective. In order to assess whether a job seeker was monitored during a given search period, we use a variable that reports for each period whether the effort was monitored and whether the job seeker was exempted from the requirement of active job search in that month. We define an individual's unemployment spell as systematically affected by the monitoring regime if at least two search periods are monitored up to the third month of unemployment (one of these two periods may refer to the month previous to the month of registration). We exclude individuals who do not meet this criterion $(7.46 \%) .{ }^{41}$

Further, individuals are only relevant for our intensive margin analysis if both their unconstrained and their constrained search was monitored. We exclude individuals who did not become subject to search monitoring under the requirement constraint, i.e. who do not report a monitored entry $s_{1}$. These are job seekers whose last monitored entry refers to the month previous to their first meeting with the caseworker $(2.06 \%)$. Conversely, we also exclude individuals whose pre-requirement search effort $s_{0}$ was not monitored, i.e. whose first monitored entry refers to the month following their first meeting with the caseworker $(2.2 \%)$.

As both the monitoring of pre-requirement effort $s_{0}$ and the monitoring of constrained effort $s_{1} \mid s_{r}$ are prescribed by law, individuals for whom one of these two entries is not monitored are most likely exempted for special cases. We therefore consider them as being irrelevant for our analysis.

\footnotetext{
${ }^{40}$ We define the first caseworker meeting as the first completed meeting of at least 30 minutes. An exception is Tessin, for which the meeting duration is not reported. We assume here that the first realized meeting after the date of registration is the first caseworker meeting.

${ }^{41}$ All percentages refer to the sample that was relevant before the sampling criterion applied.
} 


\section{A.1.2 Definition of $t_{0}$ and $t_{1}$ and Extraction of Effort Variables}

For the remaining sample, we define $t_{0}$ as the first monitored search period (we restrict it to be the earliest the month before entry into unemployment). We then define $t_{1}$ as the first monitored search period following the month of the first meeting. If the last monitored search period is the month of the first meeting, we define it as $t_{1}$. This definition implies that $t_{1}$ is not always the month following right after $t_{0}$. However, it reduces the number of search periods in which it is unclear whether the search effort was restricted or unrestricted. It thereby ensures with a high degree of certainty that the effort provided in $t_{0}$ was indeed unrestricted and the effort provided in $t_{1}$ was indeed restricted by a requirement. If $t_{0}$ or $t_{1}$ is in the month of the first caseworker meeting, some uncertainty remains on whether it refers to restricted or to unrestricted effort. We show that our results are unaffected to the exclusion of such cases, which represent a minority.

We then extract the effort variables as follows: $s_{0}$ is the effort reported for period $t_{0}, s_{1}$ is the effort reported for period $t_{1} . s_{r}$ is the required effort reported reported at period $t_{1}$. If this entry is missing at $t_{1}$, we define $s_{r}$ as the maximum required effort reported for any search period over the spell. As there are few changes in $s_{r}$ over the spell, this seems a plausible assumption. If $s_{r}$ is not reported over the entire spell, it is categorized as missing. We drop $304(0.4 \%)$ observations because they belong to a caseworker who reports more than $90 \%$ missing requirement. For the other $8.24 \%$ of job seekers for whom $s_{r}$ is missing, we impute the requirement threshold. This imputation can be undertaken in a straightforward manner.

\section{A.1.3 Imputation of Missing Requirement Levels}

In the first step of our imputation of the few missing requirement entries, we predict an individual's requirement from a linear regression on the main socio-demographics gender, education, occupation, age and a caseworker effect. We round the linear prediction $\hat{s}_{r}$ to the next integer and adjust it to account for the caseworker's requirement setting habits: each caseworker has a very limited set of requirement thresholds that she distributes to more than $10 \%$ of her cases. It is highly plausible that job seekers with missing $\hat{s}_{r}$ were assigned to one of these levels. To account for this, we proceed as follows:

1. We compile for each caseworker a candidate list of plausible requirement thresholds $C_{C W}:=\left\{s_{i} \mid\right.$ Caseworker assigns $s_{i}$ in at least $10 \%$ of her cases $\}$

2. We choose $s_{C} \in C_{C W}$ with $\left|s_{C}-\hat{s}_{r}\right|$ minimal. If $S_{C}$ is unique, we accept this value as the imputed prediction.

3. If there are two plausible requirements $S_{C}$ with the same absolute distance to the predicted value, we choose the one that the caseworker assigns more frequently.

In our empirical analysis, we show that imputed values do not drive our results, as our results are robust to their exclusion from the estimation sample. 


\section{A.2 Additional Graphs and Tables}

Figure 18: Effects of $s_{0}$ and $s_{r}-\operatorname{med}_{c}\left(s_{r}\right)$ on Job Finding Hazard (durations censored after 6 months, c.f. Table 4, column (2))

(a) Coefficients of $\gamma^{s_{0}}$ (Baseline: $s_{0}=0$ )

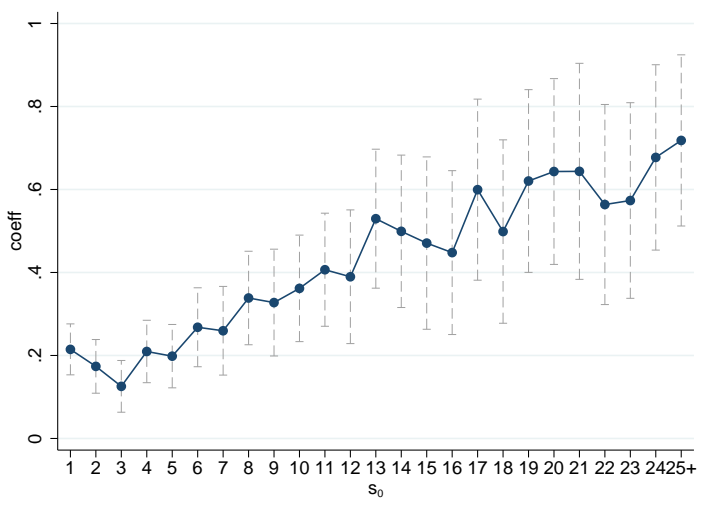

(b) Coefficients of $\sigma^{s_{r}, c}$ (Baseline: $s_{r}-\operatorname{med}_{c}\left(s_{r}\right)=0$ )

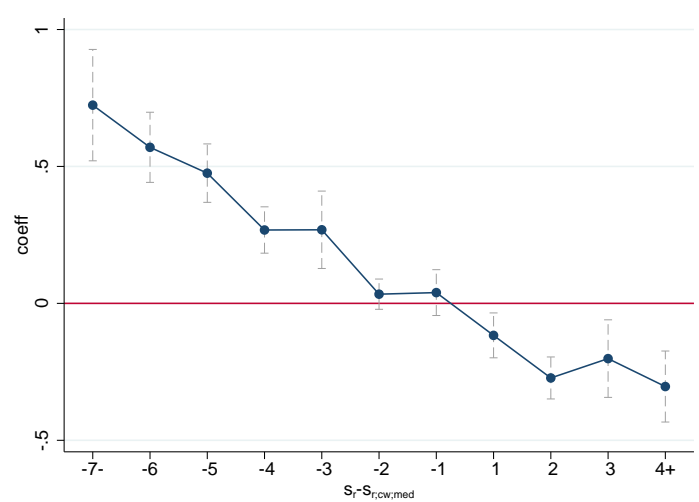

Figure 19: Empirical Job Finding Hazard (monthly intervals)

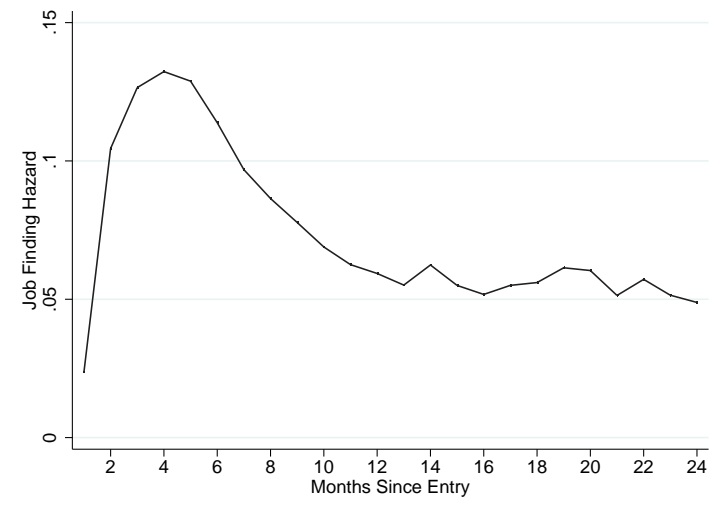


Table 12: Summary statistics: Requirement and Effort Variables $\left(\delta^{\Delta_{s_{r}}} \gamma^{s_{0}} \sigma^{s_{r}, c}\right)$

\begin{tabular}{|c|c|c|c|c|}
\hline Variable & Mean & Std. Dev. & "Min. & Max. \\
\hline$\Delta_{s_{r}}<-8$ & 0.123 & 0.329 & 0 & 1 \\
\hline$\Delta_{s_{r}} \in[-8,-7]$ & 0.029 & 0.168 & 0 & 1 \\
\hline$\Delta_{s_{r}} \in[-6,-5]$ & 0.039 & 0.194 & 0 & 1 \\
\hline$\Delta_{s_{r}} \in[-4,-3]$ & 0.055 & 0.228 & 0 & 1 \\
\hline$\Delta_{s_{r}} \in[-2,2]$ & 0.289 & 0.453 & 0 & 1 \\
\hline$\Delta_{s_{r}} \in[3,4]$ & 0.112 & 0.316 & 0 & 1 \\
\hline$\Delta_{s_{r}} \in[5,6]$ & 0.105 & 0.307 & 0 & 1 \\
\hline$\Delta_{s_{r}} \in[7,8]$ & 0.11 & 0.313 & 0 & 1 \\
\hline$\Delta_{s_{r}}>8$ & 0.137 & 0.344 & 0 & 1 \\
\hline$s_{0}=0$ & 0.223 & 0.416 & 0 & 1 \\
\hline$s_{0}=1$ & 0.03 & 0.17 & 0 & 1 \\
\hline$s_{0}=2$ & 0.041 & 0.198 & 0 & 1 \\
\hline$s_{0}=3$ & 0.047 & 0.212 & 0 & 1 \\
\hline$s_{0}=4$ & 0.068 & 0.251 & 0 & 1 \\
\hline$s_{0}=5$ & 0.062 & 0.241 & 0 & 1 \\
\hline$s_{0}=6$ & 0.06 & 0.237 & 0 & 1 \\
\hline$s_{0}=7$ & 0.045 & 0.207 & 0 & 1 \\
\hline$s_{0}=8$ & 0.074 & 0.262 & 0 & 1 \\
\hline$s_{0}=9$ & 0.039 & 0.193 & 0 & 1 \\
\hline$s_{0}=10$ & 0.055 & 0.227 & 0 & 1 \\
\hline$s_{0}=11$ & 0.032 & 0.176 & 0 & 1 \\
\hline$s_{0}=12$ & 0.032 & 0.175 & 0 & 1 \\
\hline$s_{0}=13$ & 0.018 & 0.134 & 0 & 1 \\
\hline$s_{0}=14$ & 0.019 & 0.137 & 0 & 1 \\
\hline$s_{0}=15$ & 0.015 & 0.122 & 0 & 1 \\
\hline$s_{0}=16$ & 0.013 & 0.115 & 0 & 1 \\
\hline$s_{0}=17$ & 0.014 & 0.119 & 0 & 1 \\
\hline$s_{0}=18$ & 0.012 & 0.108 & 0 & 1 \\
\hline$s_{0}=19$ & 0.008 & 0.088 & 0 & 1 \\
\hline$s_{0}=20$ & 0.012 & 0.111 & 0 & 1 \\
\hline$s_{0}=21$ & 0.007 & 0.081 & 0 & 1 \\
\hline$s_{0}=22$ & 0.007 & 0.082 & 0 & 1 \\
\hline$s_{0}=23$ & 0.005 & 0.073 & 0 & 1 \\
\hline$s_{0}=24$ & 0.006 & 0.077 & 0 & 1 \\
\hline$s_{0} \geqslant 25$ & 0.057 & 0.232 & 0 & 1 \\
\hline$s_{r}-s_{r, c w, m e d} \leqslant-7$ & 0.007 & 0.082 & 0 & 1 \\
\hline$s_{r}-\operatorname{med}_{c}\left(s_{r}\right)=-6$ & 0.013 & 0.114 & 0 & 1 \\
\hline$s_{r}-\operatorname{med}_{c}\left(s_{r}\right)=-5$ & 0.021 & 0.142 & 0 & 1 \\
\hline$s_{r}-\operatorname{med}_{c}\left(s_{r}\right)=-4$ & 0.067 & 0.25 & 0 & 1 \\
\hline$s_{r}-\operatorname{med}_{c}\left(s_{r}\right)=-3$ & 0.028 & 0.166 & 0 & 1 \\
\hline$s_{r}-\operatorname{med}_{c}\left(s_{r}\right)=-2$ & 0.105 & 0.307 & 0 & 1 \\
\hline$s_{r}-\operatorname{med}_{c}\left(s_{r}\right)=-1$ & 0.027 & 0.163 & 0 & 1 \\
\hline$s_{r}-\operatorname{med}_{c}\left(s_{r}\right)=1$ & 0.025 & 0.155 & 0 & 1 \\
\hline$s_{r}-\operatorname{med}_{c}\left(s_{r}\right)=2$ & 0.099 & 0.299 & 0 & 1 \\
\hline$s_{r}-\operatorname{med}_{c}\left(s_{r}\right)=3$ & 0.006 & 0.078 & 0 & 1 \\
\hline$s_{r}-\operatorname{med}_{c}\left(s_{r}\right)=\geqslant 4$ & 0.025 & 0.155 & 0 & 1 \\
\hline$s_{r}-\operatorname{med}_{c}\left(s_{r}\right)=0$ & 0.577 & 0.494 & 0 & 1 \\
\hline \multicolumn{5}{|l|}{$\frac{s_{r}-m e a_{c}\left(s_{r}\right)=0}{\mathrm{~N}}$} \\
\hline
\end{tabular}


Table 13: Summary statistics: Timing of Requirement Policy $\left(\eta_{t}\right)$

\begin{tabular}{lcccc}
\hline \hline Variable & Mean & Std. Dev. & Min. & Max. \\
\hline Weeks between registration and 1st meeting (rounded):1 & 0.147 & 0.354 & 0 & 1 \\
Weeks between registration and 1st meeting (rounded):3 & 0.193 & 0.395 & 0 & 1 \\
Weeks between registration and 1st meeting (rounded):4 & 0.126 & 0.332 & 0 & 1 \\
Weeks between registration and 1st meeting (rounded):5 & 0.092 & 0.289 & 0 & 1 \\
Weeks between registration and 1st meeting (rounded):6 & 0.06 & 0.237 & 0 & 1 \\
Weeks between registration and 1st meeting (rounded):7 & 0.038 & 0.191 & 0 & 1 \\
Weeks between registration and 1st meeting (rounded):8 & 0.025 & 0.155 & 0 & 1 \\
Weeks between registration and 1st meeting (rounded):9 & 0.019 & 0.137 & 0 & 1 \\
Weeks between registration and 1st meeting (rounded):10 & 0.014 & 0.116 & 0 & 1 \\
Weeks between registration and 1st meeting (rounded):11 & 0.009 & 0.092 & 0 & 1 \\
Weeks between registration and 1st meeting (rounded):12 & 0.006 & 0.078 & 0 & 1 \\
Weeks between registration and 1st meeting (rounded):13 & 0.002 & 0.048 & 0 & 1 \\
Weeks between registration and 1st meeting (rounded):0 & 0.016 & 0.127 & 0 & 1 \\
Weeks between registration and 1st meeting (rounded):2 & 0.253 & 0.435 & 0 & 1 \\
$t_{0}-$ month of registration=-1 & 0.427 & 0.495 & 0 & 1 \\
$t_{0}-$ month of registration=1 & 0.104 & 0.305 & 0 & 1 \\
$t_{0}-$ of registration=2 & 0.014 & 0.119 & 0 & 1 \\
$t_{0}-$ of registration $=0$ & 0.454 & 0.498 & 0 & 1 \\
$t_{0}-$ month of availability $<0$ & 0.763 & 0.425 & 0 & 1 \\
$t_{0}-$ month of availability $>0$ & 0.02 & 0.142 & 0 & 1 \\
$t_{0}-$ month of availability $=0$ & 0.217 & 0.412 & 0 & 1 \\
\hline \multicolumn{1}{c}{$\mathrm{N}$} & & 76404 & & \\
\hline \hline
\end{tabular}


Table 14: Summary statistics: Covariates $\left(x_{i}\right)$

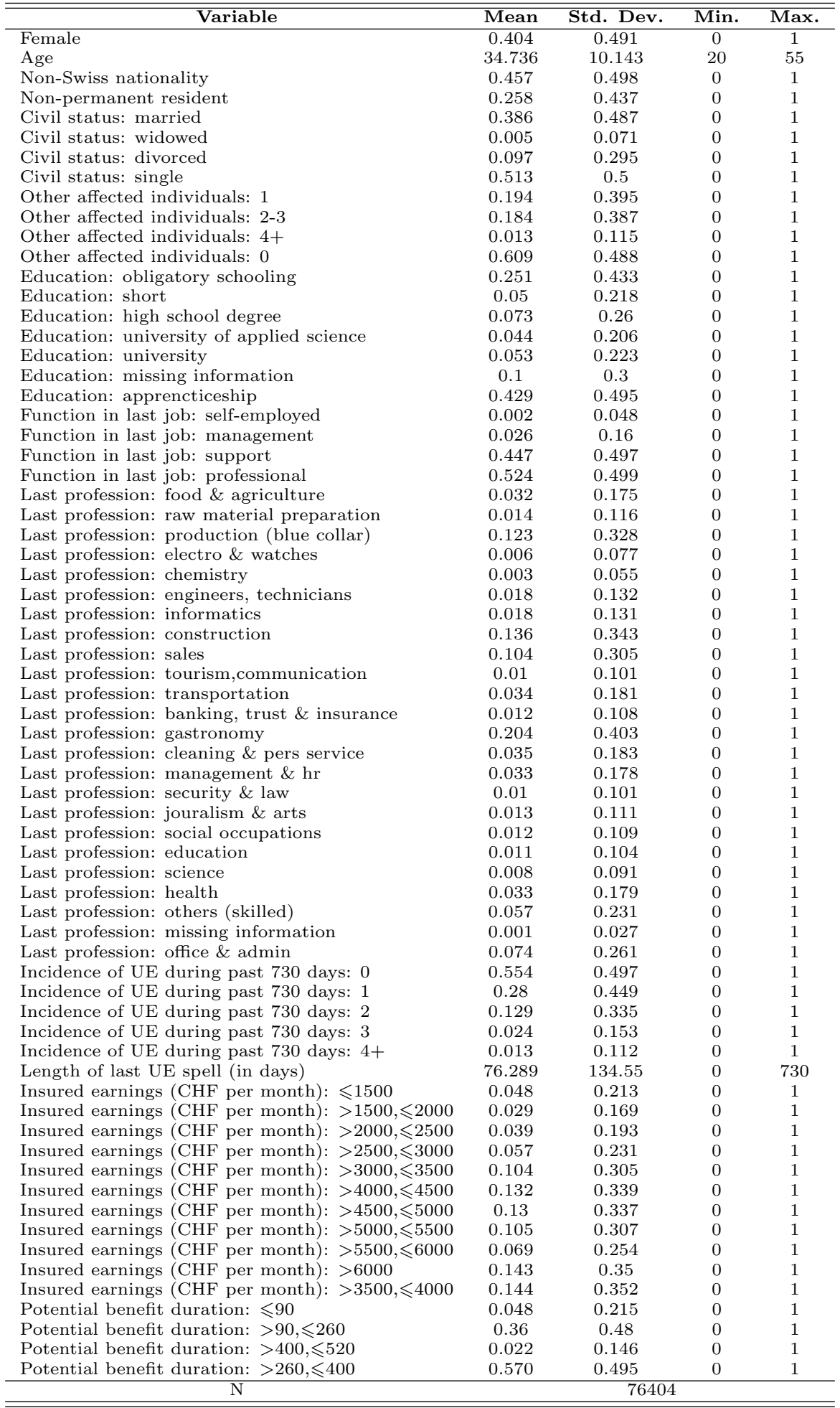

